\title{
Applications of Unmanned Aerial Vehicles in Mining from Exploration to Reclamation: A Review
}

\author{
Sebeom Park $(1)$ and Yosoon Choi * (1) \\ Department of Energy Resources Engineering, Pukyong National University, Busan 48513, Korea; \\ sebumi1v@gmail.com \\ * Correspondence: energy@pknu.ac.kr; Tel.: +82-51-629-6562; Fax: +82-51-629-6553
}

Received: 23 May 2020; Accepted: 24 July 2020; Published: 26 July 2020

\begin{abstract}
Over the past decade, unmanned aerial vehicles (UAVs) have been used in the mining industry for various applications from mineral exploration to mine reclamation. This study aims to review academic papers on the applications of UAVs in mining by classifying the mining process into three phases: exploration, exploitation, and reclamation. Systematic reviews were performed to summarize the results of 65 articles (June 2010 to May 2020) and outline the research trend for applying UAVs in mining. This study found that UAVs are used at mining sites for geological and structural analysis via remote sensing, aerial geophysical survey, topographic surveying, rock slope analysis, working environment analysis, underground surveying, and monitoring of soil, water, ecological restoration, and ground subsidence. This study contributes to the classification of current UAV applications during the mining process as well as the identification of prevalent UAV types, data acquired by sensors, scales of targeted areas, and styles of flying control for the applications of UAVs in mining.
\end{abstract}

Keywords: mine development; unmanned aerial vehicle; unmanned aerial system; mineral exploration; mineral exploitation; mine reclamation

\section{Introduction}

In recent years, unmanned aerial vehicles (UAVs) have been used for various purposes, such as safety inspection, construction site management, monitoring of infrastructure system elements, crop monitoring, invasive weed mapping, water status estimation, land-use classification, emergency response, humanitarian aid and disaster relief, conservation, disease control, healthcare, weather forecasting, telecommunications, advertising, and foodservice [1-30]. The utilization of UAVs and related research is expanding across industries owing to the significant cost reduction in vehicles and sensors and significant advances in data processing software [18].

UAVs are also important tools in the mining industry. Phases of the mining process can be divided into exploration, exploitation, and reclamation [31]. In the exploration phase, the mineralized target is identified by a team of geoscientific experts, such as geologists, mineralogists, and geophysicists. In the exploitation phase, the infrastructure for mineral production is constructed, and the ore materials are extracted using heavy equipment. Finally, in the reclamation phase, all the undesirable materials, such as waste, tailings, and contaminated topsoils, are removed from the mining area, and the underground area is appropriately filled with rock materials [32]. Because UAVs can be equipped with optical devices, cameras covering different ranges of the electromagnetic spectrum, and geophysical instrumentation, such as magnetic and natural gamma-ray sensors, they can be used for various purposes, such as geological and topographic mapping, calculation of fragmentation and the stockpile volume, and monitoring related to slope safety, road haulage, and tailings dams. 
Many studies on UAV technology have been conducted in the mining industry. Cress et al. [33] established a roadmap for using unmanned aerial systems (UASs) in geological surveys conducted in the United States. They also presented practical applications, such as monitoring of abandoned mines and waste. Lee and Choi [34] reviewed the trends and applications of UAV technology in the mining industry. In particular, the usage of UAVs for topographic surveys was presented in detail. Paisiriyuenyong [35] provided a brief explanation of how to use UAVs at each stage of mine development, and Ren et al. [36] reviewed case studies on the use of UAVs for mine operations, such as terrain surveying and 3-D modeling, land damage assessment, ecological environment monitoring, and pollution monitoring. Buczyńska [37] reviewed a few cases where UAVs were used in the reclamation phase, and Dering et al. [38] conducted a review of the UAV-based structure from motion (SfM) methodology that can be applied to the mapping and analysis of dykes and their host rocks. However, no systematic review has been performed on the applications of UAVs in mining by classifying the entire mining process into the three phases of exploration, exploitation, and reclamation.

The purpose of this study was to review academic papers on the UAV applications in mining from mineral exploration to exploitation, followed by the mine reclamation phase. The following research questions were formulated to address this objective:

- What are the current applications of UAVs in mining at the exploration, exploitation, and reclamation phases?

- What types of UAVs have been mainly used in mining?

- What types of data have been acquired by sensors for UAV applications in mining?

- What scales of the target area have been selected for UAV applications in mining?

- What styles of flying control have been used for UAV applications in mining?

Figure 1 shows the literature search process. To address the research questions, relevant research papers published in academic journals and MSC/PHD theses were searched for on the web sites of Google Scholar, SCOPUS, and Web of Science using keywords, namely, drone, UAV, UAS, application, mining, mineral, exploration, and mine. Only papers published over the past decade (June 2010 to May 2020) were considered to ensure current information from recent publications. A total of 65 research papers and MSC/PHD theses were selected with relevance to the UAV applications in mining, similarity, and content details. Incidentally, many applications of UAVs in the field of applied geology can be used in mining; however, papers without direct relevance to mining were identified and excluded from the review. The 65 studies obtained from the literature selection were categorized according to the three phases of the mining process: Exploration, exploitation, and reclamation. The analysis was conducted for each literature based on the research questions and criteria formulated in Table 1.

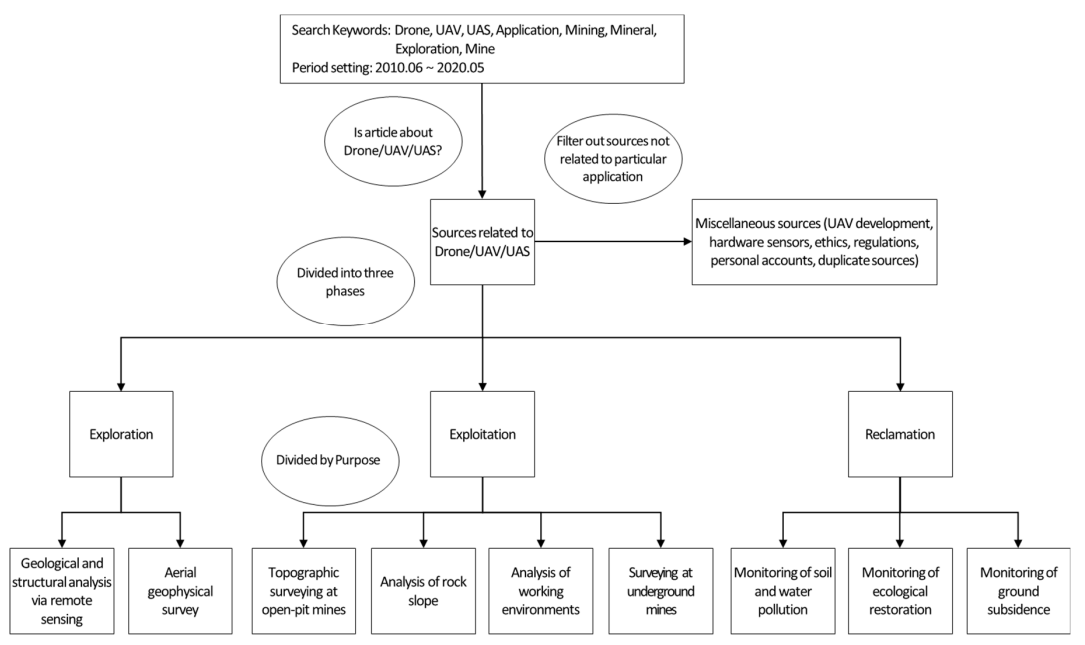

Figure 1. Process of the literature search and classification. 
Table 1. Analysis criteria for the proposed research questions.

\begin{tabular}{|c|c|c|c|c|}
\hline Application & UAV Type & $\begin{array}{l}\text { Type of Data Acquired } \\
\text { by Sensors }\end{array}$ & $\begin{array}{c}\text { Scale of } \\
\text { Target Area }\end{array}$ & $\begin{array}{c}\text { Flying } \\
\text { Control Style }\end{array}$ \\
\hline $\begin{array}{l}\text { Geological and structural analysis via } \\
\text { remote sensing }\end{array}$ & Fixed wing & $\begin{array}{l}\text { Image or video data from } \\
\text { digital camera }\end{array}$ & Regional scale $^{1}$ & Manual \\
\hline Aerial geophysical survey & Rotary wing & $\begin{array}{l}\text { Multi- and hyperspectral, } \\
\text { thermal image or data }\end{array}$ & Mine scale $^{2}$ & Autonomous \\
\hline $\begin{array}{l}\text { Topographic surveying at } \\
\text { open-pit mines }\end{array}$ & Both & Geophysics data & Zonal scale $^{3}$ & Semi-autonomous \\
\hline Rock slope analysis & & $\begin{array}{l}\text { Environmental monitoring } \\
\text { data } \\
\text { (e.g., dust, temperature) }\end{array}$ & & \\
\hline Working environment analysis & & Distance measuring data & & \\
\hline \multicolumn{5}{|l|}{ Surveying at underground mines } \\
\hline \multicolumn{5}{|l|}{ Soil and water pollution monitoring } \\
\hline \multicolumn{5}{|l|}{ Ecological restoration monitoring } \\
\hline Ground subsidence monitoring & & & & \\
\hline
\end{tabular}

\section{UAV Applications in the Mineral Exploration Phase}

During the exploration phase, the existing literature was reviewed after being divided into two categories according to the type of data that could be obtained by UAVs, namely, geological and structural analysis via remote sensing and aerial geophysical exploration.

\subsection{Geological and Structural Analysis via Remote Sensing}

In geological and structural analysis via remote sensing, UAVs are used mainly to first acquire visible, infrared, multispectral, and hyperspectral data and then process and analyze them to measure and image surface properties. Digital camera images and hyperspectral data are widely used in geology, mineral mapping, and exploration, and can be an important aspect of remote sensing.

Madjid et al. [39] presented a methodology of structure from motion (SfM) photogrammetry on aerial photographs captured by drones. They also considered the opportunities and limitations of using drones in carbonate geological studies. In addition, they conducted a case study applied to the dolomite geobodies located in Picos de Europa, northern Spain, to determine whether the proposed methodology facilitated accurate assessment of the spatial distribution and dimension of carboniferous limestone host rock. A high-resolution 3-D digital outcrop model was developed by capturing photographic images using a small drone and creating the digital surface model (DSM) with an assemblage of rectified aerial photographs. The analysis revealed that dolomite geobodies occur preferentially near strike-slip faults rather than thrust faults or specific types of limestone host rocks. The SfM photogrammetry using photographs taken by the drone presented in this study was effective in developing 3-D models of geometrically complex or important rock outcrops. It was observed to have significant capability of collecting data of outcrops located in inaccessible areas.

Beretta et al. [40] proposed a technique to automate the lithological classification of open-pit mines, using small UAVs and machine learning (ML) algorithms. They conducted a case study to classify the rock type of the opencast phosphate mine in Cajati, Brazil, using the proposed technique. To achieve this, a UAV equipped with a camera capable of recording visible light and measuring red, green, and blue (RGB) values for each pixel were adopted. First, the images captured by the UAV were used to classify materials according to the visible geological features. In addition, the input vector for constructing a model was systematized. In this study, the models were constructed and evaluated using four ML techniques: Support vector machine (SVM), k-nearest neighbor (kNN), random forest (RF), and gradient tree boost (GTB). It was verified that the precision had improved substantially compared to that of manual classification. 
Jakob et al. [41,42] developed a new toolbox for processing hyperspectral data obtained using drones and evaluated whether it could be applied to geological surveys. The toolbox provides automatic co-registration, mosaicking and geo-referencing, and topographic and illumination correction at the data processing stage. It is based on the Python language. The data processing is performed in seven steps as follows: (1) Dark calibration for extracting dark current (DC), which is randomly generated sensor noise of camera, and radiance conversion of the raw image's digital number (DN); (2) correction of distortion caused by the camera lens; (3) spatial shift correction of single band distortion caused by the UAV's flight speed, movement, and vibration; (4) mosaicking and illumination correction of overlapping images obtained through investigation; (5) geo-referencing of hyperspectral mosaic images; (6) topographic correction for reducing the influence on the local illumination within an image; and (7) conversion of hyperspectral radiance images to reflectance. For the test of the toolbox, images obtained from the Sylvestr mine in Sokolov, Czech Republic were processed. The test revealed that geometric and radiation correction provides remarkable results even in areas with low-illumination conditions and steep terrain. It has also been demonstrated that calibrated hyperspectral mosaics can be used in geological applications, such as in the detection of trends in mineralogy and soil composition.

Kirsch et al. [43] presented an integrated workflow for the geometrically and spectrally accurate combination of SfM multi-view stereo point cloud and hyperspectral data (i.e., visible and near-infrared (VNIR), short-wave infrared (SWIR), and long-wave infrared (LWIR)). Figure 2 shows a schematic processing workflow for integrating VNIR-SWIR-LWIR hyperspectral data. In addition, to validate the proposed workflow, they conducted an extensive geological field survey and collected SfM photogrammetric and hyperspectral ground-based VNIR-SWIR and LWIR, as well as UAV-based VNIR datasets. To this end, the Naundorf gravel quarry, located in the state of Saxony, Germany, was selected as a case study. First, image processing of the VNIR-SWIR data was performed based on minimum wavelength (MWL) mapping, band ratio, and endmember-based classification. Next, the MWL maps were evaluated via comparison of the absorption in the image and sample spectra. Two major lithological zones were successfully distinguished based on this analysis. Furthermore, the LWIR hyperspectral data were used to distinguish the types of rocks dominated by quartz and plagioclase.

\begin{tabular}{|l|}
\hline Drone-borne VNIR \\
$\begin{array}{l}\text { - Spectral enhancement (denoising, smoothing, dimensionality reduction) } \\
\text { - Endmember extraction and mapping }\end{array}$ \\
\hline 3D - Integration \\
\hline - RGB images \\
\hline 3D surface reconstruction (SFM-MVS photogrammetry) \\
\hline 3D RGB Point cloud \\
\hline
\end{tabular}

Figure 2. Schematic processing workflow for the integration of visible and near-infrared (VNIR)-short-wave infrared (SWIR)-long-wave infrared (LWIR) hyperspectral data (modified from [43]).

Heincke et al [44] presented the setup and results of a multi-sensor UAS capable of collecting magnetic and hyperspectral data, as part of the EU-funded multi-sensor drone (MULSEDRO) project. They collected magnetic and hyperspectral data using the UAS multi-sensor system and created DSMs that represent mean sea level (MSL) elevations of the reflective surface of features. Magnetic and hyperspectral sensors were attached to fixed-wing systems and multi-copter systems. In addition, an integrated global navigation satellite system (GNSS) receiver and inertial measurement device were 
used to measure the position and orientation of the UAS. Testing was conducted in a mining area in central Finland to evaluate the UAS constructed under the project.

Jackisch et al. [45] proposed a method for integrated data collection and processing for multi-sensor surveys that combine optical remote sensing and magnetic data. Fixed-wing and multi-copter UASs were used to investigate the characteristics of outcrops in the Otanmäki Fe-Ti-V deposits in central Finland. Two drones equipped with multispectral and hyperspectral cameras were used to detect iron-containing proxy minerals. These identified major geological features and ore extents. In addition, the magnetic field was measured at various flight altitudes using a platform equipped with a three-axis fluxgate magnetometer. Then, comparisons were made to traditional ground-based magnetic survey data to evaluate the UAS-based measurement results. The location of the mineral zone and magnetic anomalies were observed to be highly similar. It is observed that using the integrated workflow proposed in this study, mapping can be performed more simply than with the traditional ground survey method. Moreover, the investigation efficiency, spatial resolution, and reliability are high. In particular, it was verified that UAS-based surveys are approximately 20 times faster than the ground surveys when investigated at the comparable resolution.

Table 2 summarizes the reviewed literature on the application of UAVs to geological and structural analysis via remote sensing in the mineral exploration phase. Among the seven reviewed studies, two used rotary-wing UASs and the rest used both fixed and rotary-wing UASs. The reviewed studies mainly acquired digital camera images, hyperspectral images, or data. Four papers were analyzed on a regional scale and three studies on a zonal scale. For the flying control type, the UAV was operated with two autonomous controls and two semi-autonomous controls. For the remaining studies, the type is unknown.

Table 2. Summary of unmanned aerial vehicle (UAV) applications for geological and structural analysis via remote sensing.

\begin{tabular}{|c|c|c|c|c|c|c|}
\hline Reference & Year & Aim of Study & UAV Type & $\begin{array}{l}\text { Acquisition } \\
\text { Data Type }\end{array}$ & Target Area Scale & $\begin{array}{c}\text { Flying } \\
\text { Control Style }\end{array}$ \\
\hline Madjid et al. [39] & 2018 & $\begin{array}{l}\text { Presenting a photogrammetry method } \\
\text { using image taken by drones }\end{array}$ & Rotary wing & Digital camera image & Regional scale & $\underset{1}{\text { Semi-autonomous }}$ \\
\hline Beretta et al. [40] & 2019 & $\begin{array}{l}\text { Development of automation technology } \\
\text { for lithological classification using small } \\
\text { UAVs and machine learning } \\
\text { (ML) algorithm }\end{array}$ & Rotary wing & Digital camera image & Zonal scale & Unknown \\
\hline Jakob et al. [41] & 2016 & \multirow{2}{*}{$\begin{array}{c}\text { Development of toolbox for processing } \\
\text { hyperspectral data obtained } \\
\text { through drones }\end{array}$} & \multirow{2}{*}{ Both } & \multirow{2}{*}{ Hyperspectral image } & \multirow{2}{*}{ Regional scale } & \multirow{2}{*}{ Autonomous } \\
\hline Jakob et al. [42] & 2017 & & & & & \\
\hline Kirsch et al. [43] & 2018 & $\begin{array}{l}\text { Presenting an integrated workflow for } \\
\text { the geometrically and spectrally } \\
\text { combination of aerial photograph and } \\
\text { hyperspectral data }\end{array}$ & Both & $\begin{array}{l}\text { Digital camera image } \\
\text { Hyperspectral data }\end{array}$ & Zonal scale & Unknown \\
\hline Heincke et al. [44] & 2019 & $\begin{array}{l}\text { Setting up the UAS system to collect } \\
\text { magnetic and hyperspectral data }\end{array}$ & Both & $\begin{array}{c}\text { Magnetic data } \\
\text { Hyperspectral data }\end{array}$ & Zonal scale & Unknown \\
\hline Jackisch et al. [45] & 2019 & $\begin{array}{l}\text { Proposal of a data collection and } \\
\text { processing method for multi-sensor } \\
\text { survey combining optical remote } \\
\text { sensing and magnetic data }\end{array}$ & Both & $\begin{array}{l}\text { Multispectral data } \\
\text { Hyperspectral data } \\
\text { Magnetic data }\end{array}$ & Regional scale & Semi-autonomous \\
\hline
\end{tabular}

${ }^{1}$ Flying control style using both the manual mode to control drone movement using control sticks (or joystick) and the autonomous mode fully controlled by automatic controls.

\subsection{Aerial Geophysical Survey}

UAV-based geophysical surveys can be superior to fixed-wing airplane- or helicopter-based surveys for shallow-target exploration. This is particularly because of their cheaper accessibility and higher performance over challenging terrain, such as valleys, waste and ore dumps, and tailings dams [46]. Therefore, the application of UAVs for acquiring geophysical data, such as Earth's magnetic field caused by contrast of magnetic properties, is gradually increasing in mineral exploration and targeting of mineral deposits.

Eck and Imbach [47] briefly described the technical challenges of integrating high-resolution magnetic systems, UAV mission planning, and data analysis. In addition, a case study was conducted via the application of a UAV helicopter equipped with a high-resolution three-axis magnetometer at an 
actual site. The test flight was performed under challenging weather conditions, such as wind gusts and snow fall, in an open mine in Turkey where landslides occurred, and various cars were buried. An aeromagnetic survey was conducted to identify vehicles over a wide range of landslides.

Stoll and Moritz [48] considered the options that magnetometer sensor systems can be used on a UAS regarding geophysical measurements at the near surface. In addition, they conducted a UAS-based magnetic survey to detect the location of electric railway engines and mass debris of family houses buried due to landslides in open cast coal mines. As a result, the location of buried objects was successfully detected.

Malehmir et al. [46] assessed the potential of a rotary-wing UAV system to directly target iron-oxide deposits in central Sweden, considering flight flexibility and robustness. To achieve this, a walking-mode high-precision Overhauser magnetometer was attached to the rotary-wing system. Parshin et al. [49] developed heavy multirotor UAVs to increase the scale of magnetic intensity maps. These UAVs can acquire data at an altitude of $5 \mathrm{~m}$ above the terrain of interest and can be used in stable as well as under a wide range of other environmental conditions. In addition, the authors developed special software to control the UAVs' flight missions. They conducted a magnetic survey in the mountainous regions of east Siberia using the vehicle developed in the study. A comparison between airborne and ground surveys has shown that the sensitivity of the developed system to magnetic force at low altitudes enables it to detect geologically significant anomalies of the magnetic field.

Azpúrua et al. [50] proposed a new approach for generating 2-D magnetic maps using a small autonomous aerial robot with a customized fluxgate magnetometer. They evaluated its performance in a real-world scenario. In addition, they proposed a new approach toward 3-D reconstruction via SfM technology, using commercial off-the-shelf (COTS) cameras and fusion algorithms to register the magnetic data over the resulting digital elevation model (DEM). Two field experiments were conducted to evaluate the approach proposed in this study: (1) Controlled scenario with superficial anomalies and (2) a real mining scenario with underground anomalies of various depths and sizes. The results of the field experiments revealed that the new approach can achieve DEM faster than other commercial approaches and has as an accuracy similar to those of these approaches. In addition, magnetic mapping could produce potential results and be visually consistent with known anomalies in the environment.

Walter et al. [51] conducted an aeromagnetic survey using a 3-D UAV on the Shebandowan Greenstone Belt in the northwest of Thunder Bay, Ontario, Canada. The purpose of the exploration was to compare the magnetic field data measured using an UAV with the data obtained by a regional heliborne aeromagnetic survey. The exploration using the multi-rotor UAV was conducted at altitudes of 35,45 , and $70 \mathrm{~m}$ above ground level with line spacing intervals of $25 \mathrm{~m}$. Meanwhile, the regional heliborne aeromagnetic survey was carried out at an altitude of approximately $85 \mathrm{~m}$. They measured the residual magnetic intensity (RMI) using a UAV, continuously increasing the flight elevation from $35 \mathrm{~m}$ above ground level (AGL) to $45 \mathrm{~m}$ to $70 \mathrm{~m}$ AGL. Figure 3 shows RMI maps at 45 and $70 \mathrm{~m}$ AGL. Additionally, these maps show the difference between the upward continued RMI subtracted from the directly measured RMI at a 45- and 70-m flight elevation. The first vertical derivative of the measured total magnetic field was calculated directly between each of the different flight altitudes, and indirectly using predicted values for upward continuation. The study showed that the investigation using UAVs conducted at low flight altitudes can reliably obtain results with higher resolutions compared with manned aeromagnetic surveys.

Pavar et al. [52] presented the result of performing a UAV magnetometry survey on a chromite deposit located in Oman using UAV magnetometry. The purpose of the study was to verify whether magnetometry using UAVs flying at low altitudes could detect chromite deposits. They performed a UAV magnetometry survey at $20 \mathrm{~m}$ above landing zone (ALZ), and the results confirmed that the location of the chromite deposit could be sufficiently represented. However, in the UAV magnetometry survey performed at $60 \mathrm{~m} \mathrm{ALZ,} \mathrm{localizing} \mathrm{the} \mathrm{deposit} \mathrm{was} \mathrm{difficult.} \mathrm{In} \mathrm{addition,} \mathrm{they} \mathrm{determined} \mathrm{that}$ the magnetometry using a UAV could fill the observational gap between a ground-based survey and manned airborne survey. 
(a)

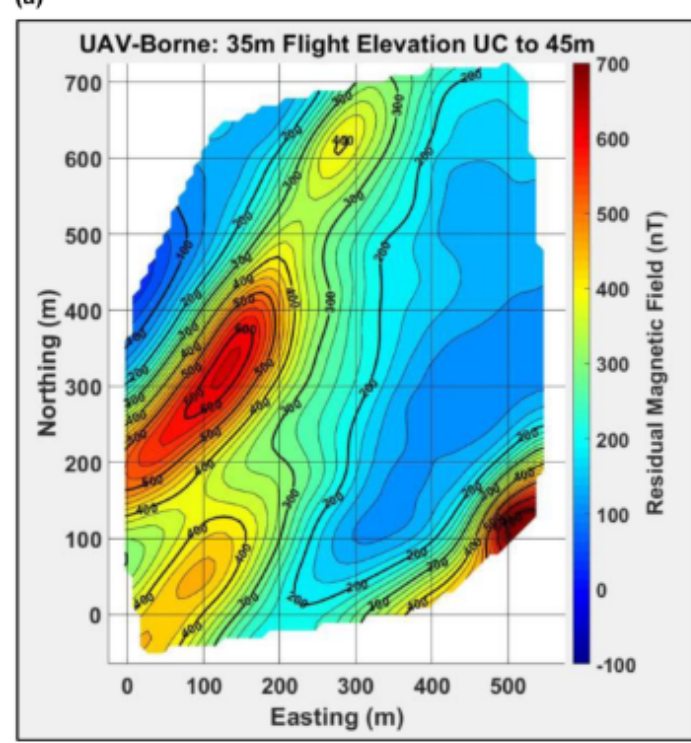

(c)

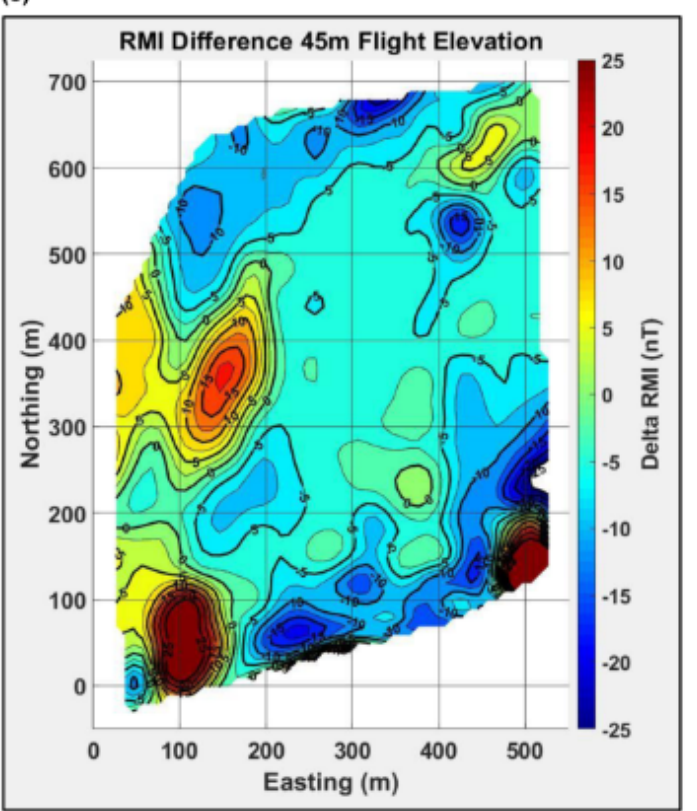

(b)

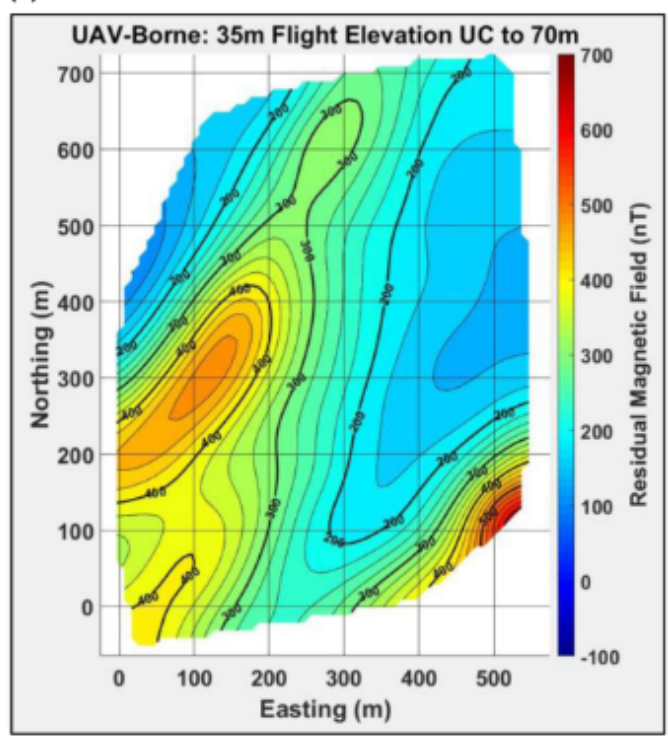

(d)

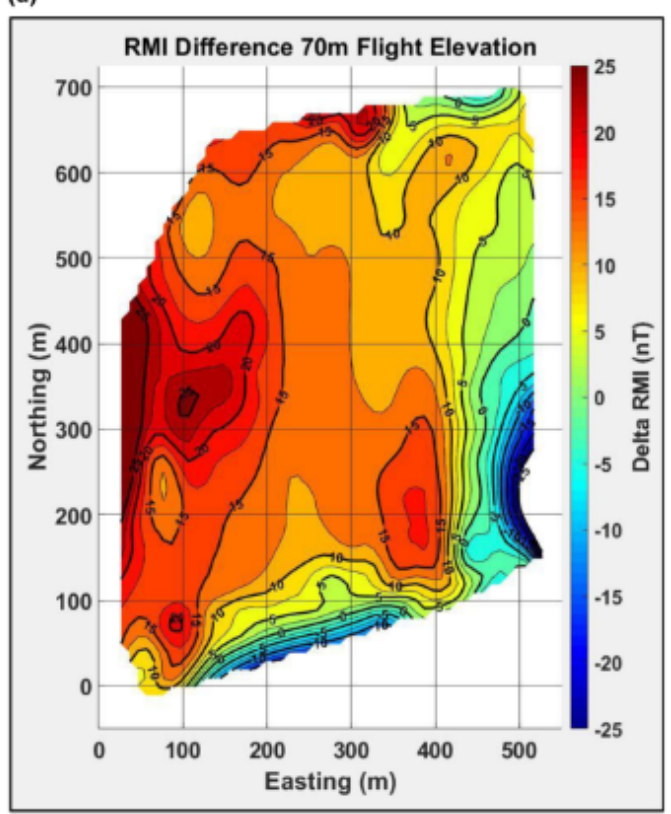

Figure 3. The 35-m flight elevation residual magnetic intensity (RMI) grid upward continued to (a) $45 \mathrm{~m}$ above ground level (AGL) and (b) $70 \mathrm{~m}$ AGL. The difference between the upward continued RMI grid subtracted from the directly measured RMI grid at (c) the 45-m flight elevation and (d) 70-m flight elevation [51].

Cunningham et al. [53] conducted aeromagnetic surveying with a UAS to evaluate the capabilities of UASs against traditional magnetic surveying systems and methods. They conducted ground surveys and UAS-based aeromagnetic surveys on zinc deposits located in Nash Creek, New Brunswick, Canada, where ground and aeromagnetic surveys have been extensively performed. As a result of comparing the upward continuation of ground magnetic data to $80 \mathrm{~m}$ AGL and UAS-based aeromagnetic data, the trends of the two data sets were perfectly matched. However, there was a diurnal correction (DC) shift of about 20-50 nT in the total magnetic intensity (TMI) between the upward continued ground data and the aeromagnetic data for the following reasons: (1) The effect of the upward sequencing algorithm used; (2) the difference in the TMI due to the time at which the investigation was performed; (3) the static magnetic source on the UAS; (4) the device drift of the magnetometer used to acquire the 
ground magnetic survey data; and/or (5) the DC shift in magnetic readings between the two different magnetometers used. In addition, compared to traditional airborne survey systems, the UAS has the advantages of being able to measure the magnetic field while flying at low altitude and low speed. This means that by flying closer to the ground, the UASs could detect a fainter signal and could also detect deeper, smaller, or weaker magnetic bodies.

Parshin et al. [54] developed a UAS that can perform a gamma ray survey at low altitudes to increase the efficiency of geological surveys in difficult-to-access landscape-morphological conditions. They compared the results of standard terrestrial gamma ray surveys with those measured using a UAS. The developed UAS was able to acquire high-quality gamma ray survey data under difficult landscape conditions, and the result yields the same level of information as the standard terrestrial gamma ray survey.

Li et al. [55] described a new prototype UAV system developed by the Institute of Geophysical and Geochemical Exploration (IGGE) that is capable of magnetic and radiometric survey. In addition, the exploration performance of the system was tested at the Treasure Mountain mine area in the northwestern Heilongjiang Province. For the safe operation of the UAV survey system, they first investigated the DEM data of the entire study area and used it to create a flight simulation. A test exploration was performed using four systems. Seven flights were conducted at an altitude of $120 \mathrm{~m}$ and an interval of $500 \mathrm{~m}$ during a week. Approximately a 3000 line-km was flown. As a result, the dynamic noise level of the magnetic data was less than $0.065 \mathrm{nT}$, the residual gain shift of the spectrometer was less than $0.27 \%$, and the residual peak position was less than $1 \%$.

Table 3 summarizes the reviewed literature on UAV applications to aero-magnetic and radiation surveys. Among the 10 papers examined, 8 applied rotary-wing UAVs, and one paper used a fixed-wing UAV. The other one used two types together. All 10 papers obtained magnetic data, and one paper also obtained radiation data. For the target area scale, six reviewed studies were analyzed on the regional scale, two on the mine scale, and two on the zonal scale. In addition, six papers used automatic flight mode and one paper applied semi-automatic mode to operate UAVs. The operation mode of the remaining studies was unknown.

Table 3. Summary of UAV applications for aerial geophysical survey.

\begin{tabular}{|c|c|c|c|c|c|c|}
\hline Reference & Year & Aim of Study & UAV Type & $\begin{array}{c}\text { Acquisition } \\
\text { Data Type }\end{array}$ & $\begin{array}{c}\text { Target } \\
\text { Area Scale }\end{array}$ & $\begin{array}{c}\text { Flying } \\
\text { Control Style }\end{array}$ \\
\hline Eck and Imbach [47] & 2011 & $\begin{array}{l}\text { Presentation of technical } \\
\text { challenges of integrating } \\
\text { high-resolution magnetic } \\
\text { system, UAV mission planning, } \\
\text { and data analysis }\end{array}$ & Rotary wing & $\begin{array}{l}\text { Magnetic } \\
\text { data }\end{array}$ & Zonal scale & Autonomous \\
\hline Stoll and Moritz [48] & 2013 & $\begin{array}{l}\text { Conducting UAS-based } \\
\text { magnetic survey to detect the } \\
\text { location of buried objects }\end{array}$ & Rotary wing & $\begin{array}{l}\text { Magnetic } \\
\text { data }\end{array}$ & Zonal scale & Semi-autonomous \\
\hline Malehmir et al. [46] & 2017 & $\begin{array}{l}\text { Evaluation of the potential of } \\
\text { rotary-wing UAV systems to } \\
\text { target iron-oxide deposits }\end{array}$ & Rotary wing & $\begin{array}{l}\text { Magnetic } \\
\text { data }\end{array}$ & $\begin{array}{l}\text { Regional } \\
\text { scale }\end{array}$ & Unknown \\
\hline Parshin et al. [49] & 2018 & $\begin{array}{c}\text { Development of heavy } \\
\text { multirotor UAVs to improve } \\
\text { the scale of aeromagnetic map }\end{array}$ & Rotary wing & $\begin{array}{l}\text { Magnetic } \\
\text { data }\end{array}$ & $\begin{array}{l}\text { Regional } \\
\text { scale }\end{array}$ & Autonomous \\
\hline Azpúrua et al. [50] & 2019 & $\begin{array}{l}\text { Presenting a new approach for } \\
\text { creating 3-D magnetic maps } \\
\text { using small UAVs }\end{array}$ & Rotary wing & $\begin{array}{l}\text { Magnetic } \\
\text { data }\end{array}$ & Mine scale & Autonomous \\
\hline Walter et al. [51] & 2020 & $\begin{array}{l}\text { Conducting aeromagnetic } \\
\text { survey using a 3-D UAV }\end{array}$ & Rotary wing & $\begin{array}{c}\text { Magnetic } \\
\text { data }\end{array}$ & $\begin{array}{c}\text { Regional } \\
\text { scale }\end{array}$ & Autonomous \\
\hline Parvar et al. [52] & 2017 & $\begin{array}{l}\text { Presenting a result of } \\
\text { performing a UAV } \\
\text { magnetometry survey }\end{array}$ & Rotary wing & $\begin{array}{l}\text { Magnetic } \\
\text { data }\end{array}$ & $\begin{array}{l}\text { Regional } \\
\text { scale }\end{array}$ & Unknown \\
\hline Cunningham et al. [53] & 2018 & $\begin{array}{l}\text { Evaluating the capabilities of } \\
\text { UASs against traditional } \\
\text { magnetic surveying systems } \\
\text { and methods }\end{array}$ & Both & $\begin{array}{l}\text { Magnetic } \\
\text { data }\end{array}$ & Mine scale & Unknown \\
\hline Parshin et al. [54] & 2018 & $\begin{array}{l}\text { Development of UAS that can } \\
\text { perform gamma survey and } \\
\text { comparison of ground-based } \\
\text { and UAS-based gamma } \\
\text { survey results }\end{array}$ & Rotary wing & $\begin{array}{c}\text { Magnetic } \\
\text { data }\end{array}$ & $\begin{array}{l}\text { Regional } \\
\text { scale }\end{array}$ & Autonomous \\
\hline Li et al. [55] & 2014 & $\begin{array}{l}\text { Proposal and performance test } \\
\text { of UAV system capable of } \\
\text { measuring magnetic force } \\
\text { and radiation }\end{array}$ & Fixed wing & $\begin{array}{l}\text { Magnetic } \\
\text { data } \\
\text { Radiation } \\
\text { data }\end{array}$ & $\begin{array}{l}\text { Regional } \\
\text { scale }\end{array}$ & Autonomous \\
\hline
\end{tabular}




\section{UAV Applications in the Mineral Exploitation Phase}

Earlier, UAV systems applied in the exploration phase were reviewed via their classification according to the methodologies for acquiring data. However, it was difficult to classify existing literature according to the type of data acquired in the exploitation stage. This section classifies existing literature, according to the purpose of using a UAV, by topographic surveying at the open-pit and underground mine, rock slope analysis, and work environment analysis.

\subsection{Topographic Surveying at Open-Pit Mines}

It is inconvenient to survey open-pit mines, which are progressing rapidly. This is because topographic surveying requires expensive surveying equipment (total station and terrestrial laser scanner) and professional technicians. However, if a UAV is used, it is possible to rapidly survey a wide area of the open pit within a reasonable budget. Most of the studies reviewed herein acquired aerial photographs using UAVs and used these photographs to generate DEM, DSM, and 3-D models of open-pit mines.

Wang et al. [56] investigated the usefulness of low-altitude UAVs for obtaining high-resolution images to reconstruct the geometry of an opencast mine. In addition, the relative error was evaluated via a comparison of the DSMs generated from the UAV point cloud and those generated from the terrestrial laser scanner (TLS) data. They developed UAV point clouds via image modeling techniques, such as SfM and a patch-based multi-view stereo (PMVS) algorithm, and then developed a DSM from the study area. While comparing these results with the DSM generated based on the TLS data, the discrepancy map of the 3-D distance based on the DSM showed that the most deviations were less than $\pm 4 \mathrm{~m}$ and that the relative error of the volume was $1.55 \%$ [56].

Cho et al. [57] verified the applicability of aerial triangulation by applying a small UAV to a mine site. To achieve this, they investigated a smectite mine located in Gyeongju-si, Gyeongsangbuk-do, Korea. They used six ground control positions to perform aerial triangulation for the study area. In addition, 448 aerial photographs were captured in the measurement area of dimensions $600 \times 380 \mathrm{~m}$. A 3-D terrain model was constructed using these. It was observed that the use of the ground control positions enabled an aerial triangulation with an accuracy of less than $1 \mathrm{~cm}$.

Lee and Choi [58,59] performed topographic surveys of different open-pit mines using rotaryand fixed-wing UAVs. Aerial photographs were acquired of the study area, and orthomosaic images and digital surface models were generated using these. In addition, the position coordinates measured using a differential global positioning system (DGPS) with respect to the ground reference point were compared with those extracted via UAV photogrammetry. The root mean square errors (RMSEs) of the $\mathrm{X}, \mathrm{Y}$, and Z-coordinates were 10 (rotary wing) and $15 \mathrm{~cm}$ (fixed wing).

Fixed-wing and rotary-wing UAVs differ in the characteristics, such as flight altitude, speed, time, and performance, of the attached cameras. Lee and Choi [60] compared the results of aerial photogrammetry, which differed for each aircraft type, in the same study area. To achieve this, a construction site located in Yangsan-si, Gyeongsangnam-do was set as the research area. Orthomosaic images and DSM with a 4-cm/pixel spatial resolution were produced using the acquired aerial photographs. Furthermore, coordinates were measured on the ground using DGPS for seven ground control points (GCPs). From a comparison between the aerial survey and ground survey, the RMSE was analyzed to be approximately $10 \mathrm{~cm}$. The fixed wing showed a relatively negligible error when the results of the two types of aerial surveying were compared. Figure 4 shows the orthographic images and DSMs of the study area for the two types of UAVs. 
Fixed-wing UAV (eBee)

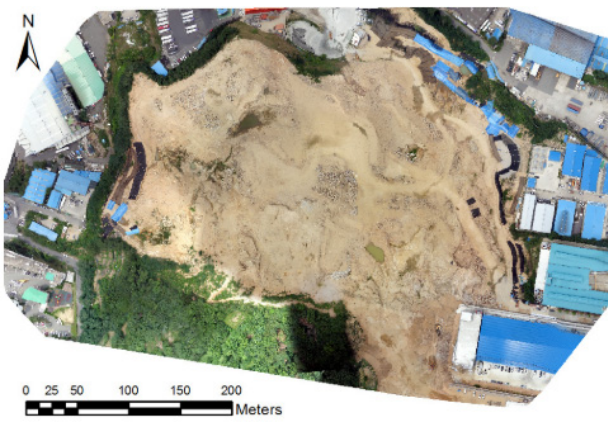

(b)

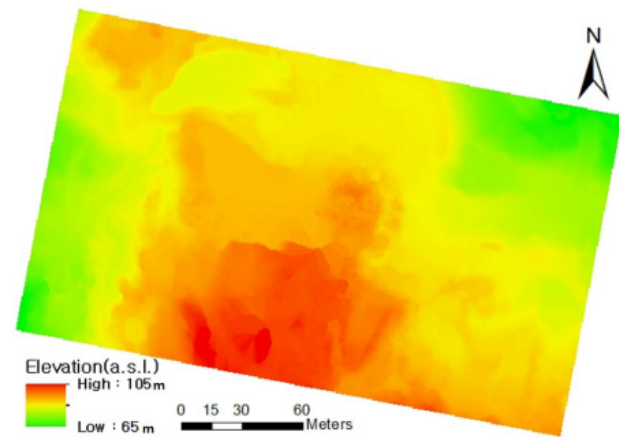

Rotary-wing UAV (Phantom2 Vision+)
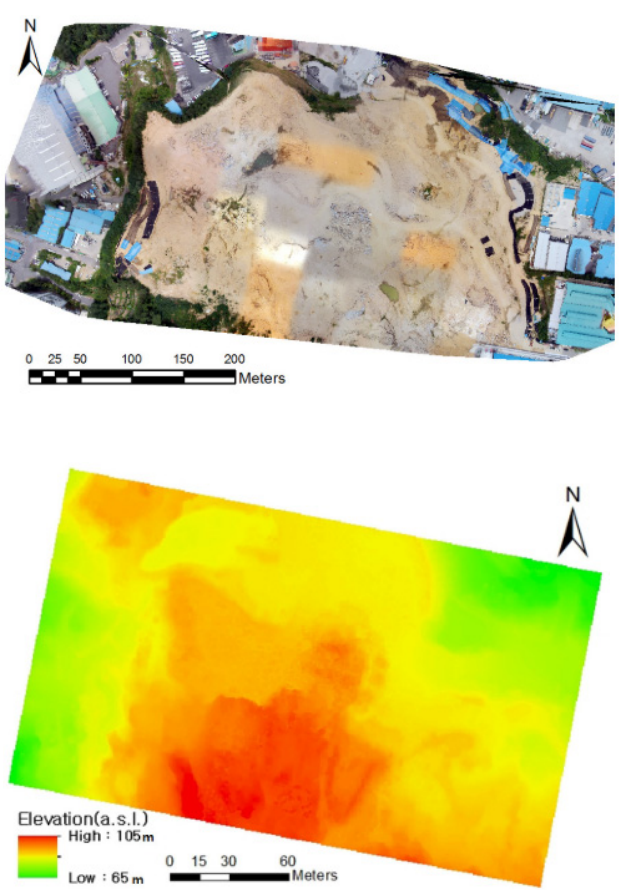

Figure 4. Results of topographic surveying for the two types of UAVs. (a) Orthomosaic image, (b) digital surface model (modified from [60]).

Chen et al. [61] investigated the characteristics of iron open-pit mines located in Beijing district, China, using high-resolution topography and landscape metric. They calculated the orientation of the terrace wall in addition to the correlation length. Furthermore, they tested a simple empirical model to derive the percentage of artificial surfaces. First, the main topographic information (DSM) was derived using UAV and SfM photogrammetry techniques. Then, the terraced areas of open-cast and open-pit mines were expressed using the slope local length of autocorrelation (SLLAC) proposed by Sofia et al. [62], a new landscape metric for the identification of terraced sites.

Rossi et al. [63] proposed a method to reconstruct the quarry terrain by utilizing nadir and oblique aerial photographs captured using a UAV, and conducted a feasibility analysis thereafter. They set the quarry in Bari, southern Italy, as the research area. They first used nadir images, and then added images obtained from off-nadir angles. They also investigated the accurate set of GCPs for georeferencing and process validation. It was observed that the final position of the point clouds, which represent the main geometries of the quarry environment in the topography reconstruction of the quarry, can achieve an accuracy of a few centimeters. A comparison of the surveys performed using a nadir and oblique image with surveys performed using a total station revealed the advantage of a better description of the shape of the quarries, surface discontinuities, and sub-vertical walls.

Chirico and DeWitt [64] evaluated the effectiveness of high-resolution orthoimage and DSMs obtained from small low-cost UAS and SfM photogrammetry, in mapping and monitoring mining sites in west Africa. The main objective of the study was to develop two-dimensional and three-dimensional geospatial data that can be used to observe mining pits and to distinguish the features of mine sites. They collected high-resolution orthoimage and DSMs using the wide-angle and narrow-field features of a view camera system and compared these. It was observed that DSMs with high precision and accuracy can be obtained using UAS images and SfM photogrammetry technology.

Gil and Frackiewicz [65] performed spatial analysis to optimize the location of the observation network points in an open-pit mine. They used UAVs for aerial photography and Quantum GIS open-source software for spatial analysis. First, an aerial photograph was captured using a UAV; 
based on this, a digital terrain model (DTM) was generated. The DTM includes heights, elevations, other geographical elements, and natural features, such as rivers and ridgelines. However, it does not represent the elevation of the reflective surfaces of trees, buildings, and other features elevated above the "Bare Earth" that is provided by the DSM. Subsequently, a spatial query and an analysis of the open-pit mine were performed using the Quantum GIS program and DEMs. The spatial analysis revealed that the use of the program substantially facilitates the initial selection of the location area for points.

In addition, various studies have been conducted to measure open-pit mines using UAV or to analyze the results. Tscharf et al. [66] proposed a workflow for automated image-based reconstruction that can generate detailed and accurate 3-D models from aerial images captured by UAVs and unordered multi-view datasets. They applied and demonstrated the proposed workflow in an open-pit mine. Xiang et al. [67] established the open-pit mine in Beijing, China, as the research area and took high-resolution aerial photographs twice using a UAV to evaluate geomorphic variations. DEMs were generated through SfM photogrammetry. The surface of the open-pit mine was analyzed by calculating the difference between two DEMs on a cell-by-cell basis and via the SLLAC method. Beretta et al. [68] evaluated the uncertainty that may appear in DSMs obtained through UAV photogrammetry. To achieve this, UAV aerial photogrammetry was performed in a small open-pit quarry located in southern Brazil. Then, it was compared with a survey method using a real-time kinetic (RTK) GNSS and laser scanning. Kršák et al. [69] carried out photogrammetry by applying a low-cost commercial UAV to open-pit mines and evaluated the accuracy of the DEM constructed through this. Ge et al. [70] presented the results of the work performed by applying UAVs in the Ulan open-cut mine and Tahmoor underground mines in New South Wales (NSW), Australia. They used a UAV to evaluate the volume of stockpile, monitor the safety of highwall slopes, and map the underground mine subsidence in these mines. Esposito et al. [71] used UAV photogrammetry to quantify the volume mined at the Sa Pigada open-pit mine in Sardinia, Italy, and to evaluate the alterations in the mine surface.

Table 4 summarizes the reviewed literature on the application of UAVs to topographic surveying in the phase of mineral exploitation. Among the 15 reviewed studies, 8 applied rotary-wing UAVs, 4 used fixed-wing UAVs, and the rest used both rotary- and fixed-wing UAVs. All 15 studies acquired digital camera images to survey the topography. Twelve articles for the target area scale were analyzed on the mine scale and three on the zonal scale. Additionally, five articles applied an autonomous control type and two articles used a semi-autonomous control type. One paper used a manual mode to operate UAVs. For the remaining studies, the type is unknown.

\subsection{Analysis of Rock Slope}

UAVs can be used for rock slope analyses (including the stability and discontinuity analysis of rock slopes that are challenging to access directly) and lithological classification of rock masses. All the existing literature reviewed in this paper used drone-based aerial photographs to map the highwall, analyze the characteristics of the slope, and survey the landslides.

McLeod [72] and McLeod et al. [73] studied the feasibility of obtaining a 3-D point cloud from video images acquired with a UAV, using SfM photogrammetry software. They used a lightweight vertical take-off and landing UAV with a miniature video camera. First, the performance of the system was evaluated by capturing aerial photographs of the city. The actual applicability was evaluated in the Wollastonite mine in Ontario, Canada. In this task, the overall low point cloud concentration is shown because the SfM processing method is applied at a relatively low pixel resolution $(640 \times 480)$. In addition, it was shown that the point on the well-represented flat surface can quantify the accuracy for a range of approximately $0.5 \mathrm{~m}$ at a distance of 25-30 $\mathrm{m}$. Although the point cloud developed by the technology was sparse, they anticipated that the overall result could be improved by enhancing the resolution of the original image and the image processing. 
Table 4. Summary of UAV applications for topographic surveying in open-pit mines.

\begin{tabular}{|c|c|c|c|c|c|c|}
\hline Reference & Year & Aim of Study & UAV Type & $\begin{array}{l}\text { Acquisition } \\
\text { Data Type }\end{array}$ & $\begin{array}{l}\text { Target } \\
\text { Area Scale }\end{array}$ & $\begin{array}{c}\text { Flying } \\
\text { Control Style }\end{array}$ \\
\hline Wang et al. [56] & 2014 & $\begin{array}{l}\text { Accuracy analysis of 3-D } \\
\text { geometry generated from } \\
\text { low-attitude UAV images }\end{array}$ & Rotary wing & $\begin{array}{c}\text { Digital } \\
\text { camera } \\
\text { image }\end{array}$ & Zonal scale & Manual \\
\hline Cho et al. [57] & 2015 & $\begin{array}{l}\text { Verification of on-site } \\
\text { applicability of aerial } \\
\text { triangulation using } \\
\text { UAV images }\end{array}$ & Rotary wing & $\begin{array}{c}\text { Digital } \\
\text { camera } \\
\text { image }\end{array}$ & Mine scale & Unknown \\
\hline Lee and Choi [58] & 2015 & $\begin{array}{l}\text { Topographic survey of open-pit } \\
\text { mine using a Rotary-wing UAV }\end{array}$ & Rotary wing & $\begin{array}{c}\text { Digital } \\
\text { camera } \\
\text { image }\end{array}$ & Mine scale & Autonomous \\
\hline Lee and Choi [59] & 2015 & $\begin{array}{l}\text { Topographic survey of open-pit } \\
\text { mine using a Fixed-wing UAV }\end{array}$ & Fixed wing & $\begin{array}{c}\text { Digital } \\
\text { camera } \\
\text { image }\end{array}$ & Mine scale & Semi-autonomous \\
\hline Lee and Choi [60] & 2016 & $\begin{array}{l}\text { Comparison of aerial } \\
\text { photogrammetry using rotary- } \\
\text { and fixed-wing UAV }\end{array}$ & Both & $\begin{array}{c}\text { Digital } \\
\text { camera } \\
\text { image }\end{array}$ & Mine scale & Semi-autonomous \\
\hline Chen et al. [61] & 2015 & $\begin{array}{l}\text { Investigation of characteristics } \\
\text { of open-pit mines using } \\
\text { topographic maps and } \\
\text { landscape metrics }\end{array}$ & Fixed wing & $\begin{array}{c}\text { Digital } \\
\text { camera } \\
\text { image }\end{array}$ & Mine scale & Autonomous \\
\hline Rossi et al. [63] & 2017 & $\begin{array}{l}\text { Proposal methodology for } \\
\text { reconstructing the topography } \\
\text { using nadir and } \\
\text { oblique imagery }\end{array}$ & Rotary wing & $\begin{array}{l}\text { Digital } \\
\text { camera } \\
\text { image }\end{array}$ & Mine scale & Autonomous \\
\hline Chirico and DeWitt [64] & 2017 & $\begin{array}{l}\text { Evaluation of high-resolution } \\
\text { orthoimage and DSM obtained } \\
\text { from UAS and } \\
\text { SfM photogrammetry }\end{array}$ & Rotary wing & $\begin{array}{l}\text { Digital } \\
\text { camera } \\
\text { image }\end{array}$ & Mine scale & Unknown \\
\hline Gil and Frackiewicz [65] & 2019 & $\begin{array}{l}\text { Optimizing the location of } \\
\text { observation network points in } \\
\text { an open-pit mine using } \\
\text { aerial photograph }\end{array}$ & Rotary wing & $\begin{array}{l}\text { Digital } \\
\text { camera } \\
\text { image }\end{array}$ & Mine scale & Unknown \\
\hline Tscharf et al. [66] & 2015 & $\begin{array}{l}\text { Suggestion of workflow for } \\
\text { image-based reconstruction } \\
\text { that can create detailed } \\
\text { 3-D models }\end{array}$ & Both & $\begin{array}{l}\text { Digital } \\
\text { camera } \\
\text { image }\end{array}$ & Zonal scale & Unknown \\
\hline Xiang et al. [67] & 2018 & $\begin{array}{l}\text { Generation of DEMs and } \\
\text { analysis of mine surface } \\
\text { through the } \\
\text { UAV photogrammetry }\end{array}$ & Fixed wing & $\begin{array}{l}\text { Digital } \\
\text { camera } \\
\text { image }\end{array}$ & Mine scale & Autonomous \\
\hline Beretta et al. [68] & 2018 & $\begin{array}{l}\text { Uncertainty evaluation of } \\
\text { digital surface models } \\
\text { obtainable through } \\
\text { UAV photogrammetry }\end{array}$ & Rotary wing & $\begin{array}{l}\text { Digital } \\
\text { camera } \\
\text { image }\end{array}$ & Mine scale & Unknown \\
\hline Kršák et al. [69] & 2016 & $\begin{array}{c}\text { Accuracy evaluation of } \\
\text { UAV-based digital elevation } \\
\text { model (DEM) }\end{array}$ & Rotary wing & $\begin{array}{c}\text { Digital } \\
\text { camera } \\
\text { image }\end{array}$ & Mine scale & Unknown \\
\hline Ge et al. [70] & 2016 & $\begin{array}{c}\text { Volume evaluation, monitoring } \\
\text { the safety of slopes, } \\
\text { and mapping the underground } \\
\text { mine using UAV }\end{array}$ & Fixed wing & $\begin{array}{l}\text { Digital } \\
\text { camera } \\
\text { image }\end{array}$ & Zonal scale & Unknown \\
\hline Esposito et al. [71] & 2017 & $\begin{array}{l}\text { Quantification of mined } \\
\text { volume, evaluation of surface } \\
\text { changes using UAV-based } \\
\text { photogrammetry }\end{array}$ & Both & $\begin{array}{c}\text { Digital } \\
\text { camera } \\
\text { image }\end{array}$ & Mine scale & Autonomous \\
\hline
\end{tabular}

Vrublová et al. [74] documented landslides or difficult-to-reach areas of mines using UAV systems and digital terrestrial photogrammetry. The Czech Nástup Tušimice mine was set up as the study area, and aerial photographs were taken automatically using a UAV. Then, they created an orthophoto and built a 3-D model of the landslide area. In addition, they used digital terrain photogrammetry for a more detailed documentation of the region of interest.

Blistan et al. [75] also indicated the usability of UAVs for the documentation of outcrops of geological rocks, including in inaccessible parts of mines. They set Slovakia's Perlite deposit Lehôtka pod Brehmi as the research area, used UAVs to image outcrops that were approximately $75 \mathrm{~m}$ tall, and generated photogrammetry documentation. The flight was set at $35 \mathrm{~m}$ above the average height of the area, and a total of 58 images were taken. Eighteen GCPs with coordinates obtained by the 
GNSS RTK method were used for locating and registering each image. The commercial software "AGISOFT PhotoScan" (Agisoft LLC, St. Petersburg, Russia) was used for image processing, and a digital terrain model of the outcrop (which is the object of the survey) was created. A comparison between the correlation between the model obtained by applying the conventional method and the model obtained through aerial photogrammetry revealed that the geological boundaries identified in the two models do not coincide with each other: The difference is as high as $1 \mathrm{~m}$. These differences were attributed mainly to the accuracy of the analog geological maps and sections and the errors in the scale and vectorization of historical maps.

Beretta et al. [76] classified rocks on the slopes of open-pit mines using UAV photogrammetry and ML. They first reconstructed the terrain through aerial photogrammetry using UAV. Then, they developed a point cloud representing the mining area. The rocks were classified into four groups: Diorite, granite, soil, and vegetation. General ML algorithms (SVM, K-NN, RF, and GTB) were used to categorize the point cloud into four classes. An analysis of the results of each ML algorithm revealed that the SVM algorithm with the radial basis function kernel had the highest accuracy. This result shows the influence of the variability on any type of visual identification on lithological materials. The regular sampling issue in 3-D where samples cannot be directly read in accumulated views has been solved with pseudo-regular samples, with a spacing between the floating points that is approximately equal to the average distance of the original dense cloud [76].

Katuruza and Birch [77] used UAV technology for mapping opencast highwalls (which present difficulties in the extraction of information because of limited access for safety reasons) and demonstrated its effectiveness. The study was conducted in Isibonelo Colliery, Mpumalanga Province, South Africa. The highwall was mapped using a drone-based digital photogrammetry technique. The raw data obtained by the UAS was processed within a relatively short period of $48 \mathrm{~h}$, and a 3-D model of the research area was generated. A comparison between the UAS-based 3-D model and the resource model revealed a good correlation.

Stead et al. [78] reviewed the application of field and remote sensing approaches for the rock slope characteristics at various scales and distances over 15 years surveyed by the Engineering Geology and Resource Geotechnics Research Group at Simon Fraser University in Vancouver, Canada. They summarized potential applications, advantages, and limitations of various remote sensing techniques for comprehensive characterizations of rock slopes. The study showed the importance of remote sensing methods, UAVs, etc. In the investigation of rock slopes. However, the traditional field methods are still important for collecting intact rock and discontinuity condition data.

Table 5 summarizes the reviewed literature on UAV applications to analyze rock slope. A total of seven documents were reviewed. Most of the literature used the rotary-wing type, and the fixed wing was used in one study. All documents obtained digital camera images and conducted a zonal-scale study. In addition, two studies operated UAVs using an autonomous mode, and the flight control style of the remaining studies was unknown.

\subsection{Analysis of Working Environments}

In addition to taking aerial photographs, UAVs can perform various tasks when installed with thermal and dust sensors, communication modules, and lights. The papers reviewed below are related to the monitoring or analysis of the working environments and workers in mines, using various sensors.

Alvarado et al. [79] developed a methodology to address the need for a more accurate approach to characterizing blasting plumes in mining sites in near-real time. Because the existing air quality monitoring method relies on a limited number of sampling locations, it is difficult to monitor the point where blasting has occurred, in real time. Therefore, dust data can be collected during flight by attaching an opto-electrical dust sensor to a small fixed-wing and multi-rotor UAV. The dust monitoring system presented in this study showed a technical performance comparable to those of industrial quality dust-monitoring devices. However, an individual calibration equation was required for the sensor to characterize the dust plumes. In addition, the tests described in this paper measured the 
concentration of PM10 (particulate matter with aerodynamic diameter $<10 \mu \mathrm{m}$ ) with a precision of $1 \mathrm{mg} / \mathrm{m}^{3}$. However, it was observed that a more accurate measurement of the concentration requires the use of other optical sensors and reference calibration with more precise equipment.

Table 5. Summary of UAV applications for analysis of rock slope.

\begin{tabular}{|c|c|c|c|c|c|c|}
\hline Reference & Year & Aim of Study & UAV Type & $\begin{array}{c}\text { Acquisition } \\
\text { Data Type }\end{array}$ & $\begin{array}{c}\text { Target } \\
\text { Area Scale }\end{array}$ & Flying Control Style \\
\hline McLeod [72] & 2012 & \multirow{2}{*}{$\begin{array}{c}\text { Presenting the possibility to } \\
\text { create a 3-D point clouds from } \\
\text { video images acquired } \\
\text { with UAV }\end{array}$} & Rotary wing & $\begin{array}{l}\text { Digital } \\
\text { camera } \\
\text { image }\end{array}$ & Zonal scale & Unknown \\
\hline McLeod et al. [73] & 2013 & & Rotary wing & $\begin{array}{l}\text { Digital } \\
\text { camera } \\
\text { image }\end{array}$ & Zonal scale & Unknown \\
\hline Blistan et al. [75] & 2016 & $\begin{array}{l}\text { Proposal of UAV's usefulness } \\
\text { in investigating outcrops of } \\
\text { geological rocks }\end{array}$ & Rotary wing & $\begin{array}{l}\text { Digital } \\
\text { camera } \\
\text { image }\end{array}$ & Zonal scale & Autonomous \\
\hline Beretta et al. [76] & 2019 & $\begin{array}{l}\text { Classification of rock on the } \\
\text { slope of using aerial } \\
\text { photogrammetry and } \\
\text { machine learning }\end{array}$ & Rotary wing & $\begin{array}{l}\text { Digital } \\
\text { camera } \\
\text { image }\end{array}$ & Zonal scale & Unknown \\
\hline Stead et al. [78] & 2019 & $\begin{array}{l}\text { Review of application of field } \\
\text { and remote sensing approaches } \\
\text { for rock slope characteristics }\end{array}$ & Rotary wing & $\begin{array}{l}\text { Digital } \\
\text { camera } \\
\text { image }\end{array}$ & Zonal scale & Unknown \\
\hline
\end{tabular}

Bamford et al. [80] presented a concept for measuring rock fragmentation using UAVs and conducted laboratory-scale tests. The purpose of the study was to highlight the advantages of aerial rock fragmentation analysis using a UAV in terms of prediction accuracy and time effort. They explained the procedure for collecting data using the UAV system, and the UAV system configuration. Under the laboratory-scale tests, they first collected rock and pile distribution and information using a UAV system, and manually photographed the rocks and piles for comparative analysis. A comparison of the method using the UAV system and the existing method revealed that the UAV system can measure rock fragmentation within $6 \%$ of the accuracy of the existing method, which deviates by up to $14 \%$ from the actual distribution. In addition, the time required was within $20 \%$. Based on these results, it is anticipated that rock fragmentation analysis using UAV can improve the reliability of measurement and reduce sampling errors without disturbing the mining process.

Bamford et al. [81] also investigated the application of a UAV using artificial lighting to measure rock fragmentation in poor lighting conditions, such as those during night work or underground mine work. They investigated the effect of lighting conditions on the analysis of aerial rock fragments through indoor and outdoor experiments. The experiment revealed that the lighting conditions substantially influence the accuracy of the image analysis technique for measuring rock fragmentation. Furthermore, it was verified that the prediction accuracy was improved when artificial lighting was installed on a rock pile or attached to a UAV system.

Motepe [82] proposed a UAV system capable of conducting search and rescue missions at an accident site of a mine. This was aimed at reducing human injury, direct fatalities, and fatalities owing to delays in treatment that may occur in the mine. The UAV communicates with the control station located on the ground via Wi-Fi and is equipped with a vision system that includes an algorithm that can detect people, so that the rescuer can be informed of their presence. The human detection system is based on the Haar-Cascade classifiers, and the developed model has a very low false alarm rate. During testing of the UAV system, it was possible to detect humans with a probability of approximately $97 \%$, and false detections occurred with a probability of $2.5 \%$. 
Péter et al. [83] analyzed the usefulness of drones for rescue from the perspective of an open-air mine disaster. They surveyed and compared a variety of parameters, such as flight operational time, distance, and working loads, across a variety of products from leading drone companies. In addition, they were compared to rescue helicopters applied to real open-pit mines. Drones would not be able to completely replace rescue helicopters because drones are incapable of transporting people or objects or travelling long distances similar to rescue helicopters. However, drones have the advantage of having the capability to conveniently access areas difficult to reach by helicopters. This is because of the rapid take-off and landing capability and the small size of the aircraft. Therefore, it was concluded that it is highly efficient to operate a drone as an assistance unit of a rescue helicopter.

Because mines have complex topologies, setting up wireless communication with a traditional rescue robot is a highly complex task. Therefore, in the case of a mine emergency, it is highly challenging to perform rescue and recovery operations in a timely manner. Ranjan et al. [84] proposed a UAV-based multihop emergency communication system to support miners and rescue team members in an emergency. They tested the emergency communication system by dividing the experiment into three scenarios: No UAV, one UAV, and two UAVs. To evaluate each scenario, performance indicators were considered, such as end-to-end packet error rate (PER), successful end-to-end per packet delay, and the number of retransmissions. The evaluation verified that the performance of the UAV-based system was improved in terms of the packet error rate, end-to-end delay, and per packet retransmission.

Table 6 summarizes the six reviewed studies on the application of UAVs to analyze working environments in the phase of mineral exploitation. For the UAV type, four applied rotary-wing UAVs, one used both, and another was unknown. Among the six reviewed studies, three studies obtained digital camera images and two papers acquired dust data and communication data. In terms of the target area scale, three papers were analyzed on the mine scale, two on the zonal scale, and one on the regional scale. In addition, four studies used an autonomous flight mode, one study used a semi-autonomous flight mode, and the other used the manual flight mode.

Table 6. Summary of UAV applications for analysis of working environments.

\begin{tabular}{|c|c|c|c|c|c|c|}
\hline Reference & Year & Aim of Study & UAV Type & $\begin{array}{c}\text { Acquisition } \\
\text { Data Type }\end{array}$ & $\begin{array}{c}\text { Target } \\
\text { Area Scale }\end{array}$ & $\begin{array}{c}\text { Flying } \\
\text { Control Style }\end{array}$ \\
\hline Alvarado et al. [79] & 2015 & $\begin{array}{l}\text { Development of a methodology } \\
\text { to characterize the blasting } \\
\text { plumes in near-real time }\end{array}$ & Both & Dust data & $\begin{array}{l}\text { Regional } \\
\text { scale }\end{array}$ & Semi-autonomous \\
\hline Bamford et al. [80] & 2017 & $\begin{array}{l}\text { Suggestions for measuring rock } \\
\text { fragmentation using UAVs }\end{array}$ & Rotary wing & $\begin{array}{l}\text { Digital } \\
\text { camera } \\
\text { image }\end{array}$ & Zonal scale & Autonomous \\
\hline Bamford et al. [81] & 2017 & $\begin{array}{l}\text { Evaluation of applicability of } \\
\text { UAV using artificial lighting to } \\
\text { measure rock fragmentation }\end{array}$ & Rotary wing & $\begin{array}{l}\text { Digital } \\
\text { camera } \\
\text { image }\end{array}$ & Zonal scale & Autonomous \\
\hline Motepe [82] & 2013 & $\begin{array}{l}\text { Proposal of a UAV system } \\
\text { capable of conducting search } \\
\text { and rescue missions at a mine's } \\
\text { accident site }\end{array}$ & Rotary wing & $\begin{array}{l}\text { Digital } \\
\text { camera } \\
\text { image }\end{array}$ & Mine scale & Manual \\
\hline Péter et al. [83] & 2016 & $\begin{array}{l}\text { Analysis of the usefulness of } \\
\text { drones for rescue from the } \\
\text { perspective of an open-pit mine } \\
\text { disaster }\end{array}$ & Rotary wing & - & Mine scale & Autonomous \\
\hline Ranjan et al. [84] & 2018 & $\begin{array}{l}\text { Proposal of UAV based } \\
\text { multihop emergency } \\
\text { communication system }\end{array}$ & Unknown & $\begin{array}{l}\text { Communication } \\
\text { data }\end{array}$ & Mine scale & Autonomous \\
\hline
\end{tabular}

\subsection{Surveying at Underground Mines}

There are few UAVs and instruments that are dedicated to underground environments. Similar environments typically have low-visibility conditions, confined openings, magnetic interference, and an absence of GPS coverage [85]. However, if UAV systems are equipped with high-resolution cameras, LED lights, and thermal sensors, useful information, such as image (thermal, spectral, etc.), distance, 
inertial measurement unit (IMU), and sound navigation and ranging (SONAR) data, can be obtained in areas that are difficult to be accessed by mine workers.

Kanellakis and Nikolakopoulos [86] used UAVs to enable vision-based mine inspections. Thereby, they presented an assessment of the current technology of visual localization systems for underground mining. In addition, they verified whether UAV-based localization technology can be applied in harsh and challenging environments, while using reliable and low-cost existing methods and technologies. To achieve this, an experiment was conducted on a visual localization system at an iron ore mine in Kiruna, Sweden, one of the largest mines in Europe. The experimental results showed that stereo cameras can be used for automated UAVs. However, drift errors accumulated in the results. Meanwhile, it has been demonstrated that the monocular camera approach can be used successfully under certain constraints.

Freire and Cota [87] designed a UAV to capture images of areas of underground mines that are rendered inaccessible due to mining and blasting. This UAV features a balloon filled with helium gas, a quadcopter propeller with remote-control powerful LED lighting, a rechargeable battery, a remote-control camera, an image stabilizer, and a radio frequency transceiver for control and image visualization. In addition, owing to the characteristic of the underground mine, the equipment could fly without using GPS and at variable low speeds to prevent collisions with rock walls and support elements. The test was conducted at a sublevel stope with a width of 5-6 m, dip of $45^{\circ}$, and with $20 \mathrm{~m}$ between sublevels. The LED lighting attached to the UAV was sufficient to reveal the details of the rock walls, rock mass structures, evidence of blasting, and support elements. In addition, no signal loss occurred during flight even when the balloon disappeared from direct view.

Raj [88] proposed a monitoring system using drones to improve the safety of monitoring equipment, deliver fast and real-time monitoring results, and minimize human exposure to unsafe underground conditions. In addition, this study demonstrated that it is possible to survey and monitor using drones in underground mines where GPS is non-functional, light conditions are low, and spaces are confined. The main contents of his research are as follows: (1) Development of image capture and control technology for application in narrow spaces and underground environments; (2) development of a solution that can utilize drones even in dark environments, using specially designed lighting attached to the drones; (3) image capture with significant quality and quantity to create three-dimensional point clouds; and (4) evidence of geotechnical rock mass characteristics and rock mass movement by processing the generated point clouds data. The study revealed that the point clouds created using the drone were highly similar to those created using the light detection and ranging (LiDAR) scanner. However, the noise appears to occur more while using the drone. Notwithstanding the relatively lower point resolution, important geotechnical information was obtained, including fracture direction and variation detection.

Turner et al. [85] created a 3-D model by thermal imagery using a UAV in an underground mine. They also conducted a study on the identification of geological data in a photogrammetric model. This study showed that off-the-shelf technologies could be used to obtain high-quality data for geotechnical analysis. The UAV system includes obstacle detection, lighting, thermal imagery, and software. Depending on the geological structure or fracture in the rock mass, the material may deform, and a difference in temperature may occur. Consequently, a thermal camera can be used to verify the temperature contrasts and assess the stability of the underground opening. The use of a UAV was tested at Barrick Golden Sunlight Mine, Whitehall, Montana, USA. The study revealed that the thermal image lacks the refinement and point density of the RGB model. However, it was more convenient to detect loose ground and detailed structures. The study revealed that a good combination of off-the-shelf technologies with UAVs can effectively perform photogrammetry and identify geological data in underground mining environments.

Turner et al. [89] also investigated the detection and quantification of geological discontinuities in hard rock masses, using thermal and multispectral images obtained using UAVs. Multiple thermal; 
multispectral; red, green, and blue (RGB); and LiDAR data sets were acquired in the same study area. They used this data to generate georeferenced 3-D point clouds and meshes, and to map discontinuities.

In addition to these studies, Mitchell and Marshall [90] presented potential applications of UAVs in underground mines. They also developed a prototype of UAVs capable of automatic rotation for underground mining scanning. Azhari et al. [91] analyzed the construction of a UAV sensor suite that can generate rough 3-D models in real time using SONAR data and provide operators with high contextual awareness.

Table 7 summarizes the reviewed literature on UAV applications of surveying in underground mines. All seven reviewed studies conducted the study by using UAVs of the rotary-wing type. Various data, such as distance data, digital camera images, thermal images, and SONAR data, were acquired for topographic surveying in underground mines. Half the papers reviewed were analyzed on a mine scale and the other half on a zonal scale. In addition, two studies used an autonomous flight mode, two papers used a semi-autonomous mode, and the rest of the studies were unknown.

Table 7. Summary of UAV applications for surveying in underground mines.

\begin{tabular}{|c|c|c|c|c|c|c|}
\hline Reference & Year & Aim of Study & UAV Type & $\begin{array}{l}\text { Acquisition } \\
\text { Data Type }\end{array}$ & $\begin{array}{c}\text { Target } \\
\text { Area Scale }\end{array}$ & Flying Control Style \\
\hline $\begin{array}{c}\text { Kanellakis and } \\
\text { Nikolakopoulos [86] }\end{array}$ & 2016 & $\begin{array}{l}\text { Assessment of technology for } \\
\text { visual localization systems for } \\
\text { underground mining }\end{array}$ & Rotary wing & $\begin{array}{l}\text { Distance } \\
\text { data }\end{array}$ & Mine scale & Autonomous \\
\hline Freire and Cota [87] & 2017 & $\begin{array}{l}\text { UAV design for imaging in } \\
\text { areas inaccessible to } \\
\text { underground mine due to } \\
\text { mining and blasting }\end{array}$ & Rotary wing & $\begin{array}{l}\text { Digital } \\
\text { camera } \\
\text { image }\end{array}$ & Zonal scale & Unknown \\
\hline Raj [88] & 2019 & $\begin{array}{l}\text { Proposal of drone-based } \\
\text { monitoring system that can be } \\
\text { used in underground mines }\end{array}$ & Rotary wing & $\begin{array}{l}\text { Digital } \\
\text { camera } \\
\text { image }\end{array}$ & Zonal scale & Semi-autonomous \\
\hline Turner et al. [85] & 2018 & $\begin{array}{l}\text { Creation of 3-D model of } \\
\text { underground mine using FLIR } \\
\text { (forward looking } \\
\text { infrared) image }\end{array}$ & Rotary wing & $\begin{array}{l}\text { Thermal } \\
\text { image }\end{array}$ & Zonal scale & Unknown \\
\hline Turner et al. [89] & 2020 & $\begin{array}{l}\text { Proposal of a method to detect } \\
\text { and quantify geological } \\
\text { discontinuities using thermal } \\
\text { and multispectral images }\end{array}$ & Rotary wing & $\begin{array}{l}\text { Thermal } \\
\text { image } \\
\text { Multispectral } \\
\text { image }\end{array}$ & Zonal scale & Semi-autonomous \\
\hline $\begin{array}{l}\text { Mitchell and } \\
\text { Marshall [90] }\end{array}$ & 2017 & $\begin{array}{l}\text { Prototype development of UAV } \\
\text { for underground } \\
\text { mining scanning }\end{array}$ & Rotary wing & $\begin{array}{l}\text { Digital } \\
\text { camera } \\
\text { image }\end{array}$ & Mine scale & Autonomous \\
\hline Azhari et al. [91] & 2017 & $\begin{array}{l}\text { Generation of 3-D models of } \\
\text { underground UAV operating } \\
\text { environments using } \\
\text { SONAR data }\end{array}$ & Rotary wing & $\begin{array}{l}\text { IMU data } \\
\text { SONAR data }\end{array}$ & Mine scale & Unknown \\
\hline
\end{tabular}

\section{UAV Applications in the Mine Reclamation Phase}

The final phase of the mining process included forest and vegetation restoration, groundwater level restoration, and environmental monitoring, in conjunction with mine closure. In this study, according to the type of restoration work performed by applying the UAV system, the existing literature was categorized into soil and water pollution monitoring, ecological restoration monitoring, and ground subsidence monitoring.

\subsection{Monitoring of Soil and Water Pollution}

The existing literature related to soil and water pollution monitoring reveals that UAVs are used to mainly acquire hyperspectral images and investigate the concentration of hazardous minerals. In addition, it was observed that UAVs are being used for data acquisition via sensors installed on them as well as for tasks, such as water sampling.

Martin et al. [92] used a UAV to map gamma radiation from uranium veins located in Cornwall, England. Sourt Terras, one of the mines containing the vein, was a major source of uranium and radium ores between 1870 and 1930. Currently, these regions are characterized by localized radioactivity. Furthermore, the documentation of the region is outdated, hindering the application of traditional 
survey methods. Therefore, incident radiation was recorded by attaching a lightweight gamma-ray spectrometer to the UAV. The data was stored on the device and transmitted in real time to the user of the remote base station. Thereby, they were able to generate high-resolution radiation maps at significantly faster collection rates over large areas using UAV-based systems. In addition, it was shown that the attenuation effect of incident gamma rays by a person carrying a detector, which is observed in conventional ground-based surveys, can be eliminated.

Fang et al. [93] presented a method of using hyperspectral images obtained with UAV and regression analysis, to search and map the concentration of Fe accumulated in the soil. They set the Malan Fe mine in Hevei Province, China, as the experimental area to verify the proposed method. They first developed their own GPU-based Python script to preprocess UAV-based hue saturation intensity (HSI) images. They then integrated it into the PhotoScan platform. Subsequently, the model was evaluated in an unbiased manner through the cross-validation estimation method. A model was selected for optimal prediction accuracy. The regression models evaluated were partial least squares (PLSR), support-vector machine (SVM), and an artificial neural network (ANN). The evaluation revealed the PLSR model to be the most suitable for estimating Fe concentrations. Finally, feature extraction and selection were applied to improve the accuracy of estimation.

Jackisch et al. [94] investigated pyrite and its consecutive weathering products in mining waste, using a lightweight drone system. The area surveyed was a re-cultivated tailings area in the Sokolov lignite district in the Czech Republic. Four field and flight tests were conducted. PH, X-ray fluorescence (XRF), and reflectance analysis were performed in the field to verify the drone system, and accurate information was obtained for samples characterized under laboratory conditions. Hyperspectral data were processed and corrected for atmospheric, topographic, and illumination effects using an accurate DEM. However, the high-resolution point clouds and DEMs were constructed via drone-based RGB data and SfM multi-view-stereo photogrammetry. Through the classification of the hyperspectral image data, it was possible to verify the presence of jarosite and goethite in the experimental area. Figure 5 shows the combination of acid mine drainage detection results obtained in the study.

Aerial drones or UAVs have the following advantages in monitoring pit lakes: (1) Reduce the risks associated with sampling water, (2) reduce the costs associated with sampling, and (3) increase the frequency of data acquisition. Therefore, Castendyk et al. [95] used drones to select the sampling depth of the pit lake in a mine. That is, the optimal sampling depth is selected according to the temperature and specific conductance of the field, which are collected using a drone prior to water sampling. The parameters of the physical condition of the pit lake are transmitted to the investigator. They conducted research on two pit lakes located in northwest USA. Both are located in places difficult to access by humans. First, the drone was equipped with a conductivity-temperature-depth (CTD) probe capable of measuring up to a depth of $100 \mathrm{~m}$. A water sampling device capable of collecting $2 \mathrm{~L}$ of water samples from a depth of up to $120 \mathrm{~m}$ was attached. For the first pit lake, three water samples were collected at depths of 0,28 , and $56 \mathrm{~m}$. Subsequent laboratory results showed that all the samples were homogeneous. However, the sampling results of the second pit lake showed various water chemistries and persistence of summer stratification depending on the depth. Based on the experimental results, it can be concluded that using UAVs to monitor pit lakes can provide important information on the behavior and water quality of pit lakes to managers.

Table 8 summarizes the reviewed literature on the application of UAVs for monitoring soil and water pollution in the mine reclamation phase. Among the four reviewed studies, two applied rotary-wing UAVs, one used both rotary- and fixed-wing UASs, and one paper was unknown. For the acquisition data type, there were various data, such as gamma spectrum data, hyperspectral images, and water data. Three papers were analyzed on the zonal scale and one on the regional scale. Finally, two studies used an autonomous flight mode, and the rest of the studies were unknown. 


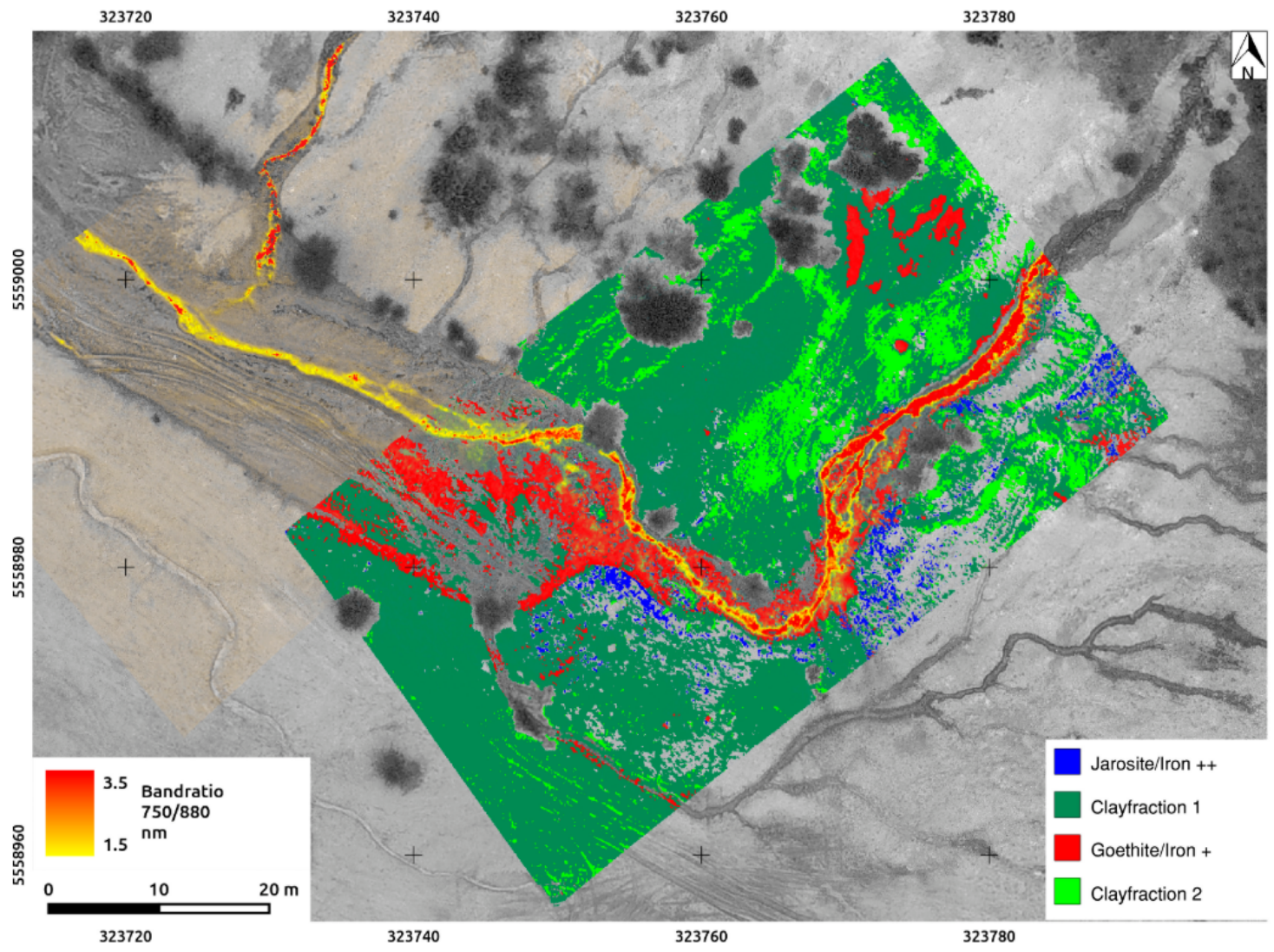

Figure 5. The combined result of three hue saturation intensity (HSI) images [94].

Table 8. Summary of UAV applications for monitoring of soil and water pollution.

\begin{tabular}{|c|c|c|c|c|c|c|}
\hline Reference & Year & Aim of Study & UAV Type & $\begin{array}{c}\text { Acquisition } \\
\text { Data Type }\end{array}$ & $\begin{array}{c}\text { Target } \\
\text { Area Scale }\end{array}$ & Flying Control Style \\
\hline Martin et al. [92] & 2015 & $\begin{array}{l}\text { Mapping the gamma radiation } \\
\text { using UAV attached a } \\
\text { lightweight } \\
\text { gamma-ray spectrometer }\end{array}$ & Rotary wing & $\begin{array}{l}\text { Gamma } \\
\text { spectrum } \\
\text { data }\end{array}$ & $\begin{array}{l}\text { Regional } \\
\text { scale }\end{array}$ & Autonomous \\
\hline Fang et al. [93] & 2019 & $\begin{array}{l}\text { Mapping of Fe concentration in } \\
\text { soil using hyperspectral image } \\
\text { and regression analysis }\end{array}$ & Unknown & $\begin{array}{l}\text { Hyperspectral } \\
\text { image }\end{array}$ & Zonal scale & Unknown \\
\hline Jackisch et al. [94] & 2018 & $\begin{array}{l}\text { Investigation of pyrite and its } \\
\text { consecutive weathering } \\
\text { products in mining waste } \\
\text { using drones }\end{array}$ & Both & $\begin{array}{l}\text { Hyperspectral } \\
\text { image }\end{array}$ & Zonal scale & Autonomous \\
\hline Castendyk et al. [95] & 2019 & $\begin{array}{l}\text { Selection of the optimal water } \\
\text { sampling depth according to } \\
\text { the temperature and specific } \\
\text { conductance of the pit lake }\end{array}$ & Rotary wing & $\begin{array}{c}\text { Water } \\
\text { temperature } \\
\text { data } \\
\text { Water } \\
\text { sample }\end{array}$ & Zonal scale & Unknown \\
\hline
\end{tabular}

\subsection{Monitoring of Ecological Restoration}

In the restoration phase, the use of UAVs in ecological restoration monitoring appeared to be prominent. In the case of monitoring related to ecological restoration, it was observed that the UAV system was used to understand the distribution of vegetation via the acquisition of aerial photographs, multispectral images, or near infrared images.

Lee et al. [96] used UAS-based photogrammetry to analyze and monitor variations in the ecological restoration area of open-pit limestone mines located in Gangwon-do, Korea. They performed aerial laser surveying, photogrammetry using a fixed-wing drone, and photogrammetry using a rotary-wing drone, three times. Thereby, orthophotos were collected, DSM and point clouds were generated, 
and variations in the ecological restoration area were monitored through comparisons with orthophoto and DEMs. The vegetation distribution area extracted from the RGB orthophoto using the excessive green index and visible atmospherically resistant index revealed that the vegetation had increased by approximately $10-30 \%$ when compared to the area ratio. In addition, an analysis of the DEM generated using the drone-based photogrammetry verified that it is highly similar to the restoration plan line. This implies that the restoration process is complete.

Urban et al. [97] compared the data obtained for the spoil heap area during the leaf-off period using two UAVs and the results of aerial photogrammetry. In addition, to compare the accuracy of UAV-based point clouds, a new approach was proposed to perform statistical estimation without additional validation data (e.g., GNSS survey). They investigated the influence of the vegetation cover and selected typical vegetation areas, such as forest, grass, and bush, to determine random errors in the data obtained through the UAV system. A comparison of the individual data in grassy areas revealed that the accuracy of the difference was approximately $0.03 \mathrm{~m}$ and that the average shift was from 0.01 to $0.08 \mathrm{~m}$. Meanwhile, the accuracy of the data in the forest terrain was approximately $0.04 \mathrm{~m}$, which was lower than that in the lawn. The data on the terrain of the bush appeared to be more precise than those of the grassy and forested areas.

Moudrý et al. [98] used two fixed-wing UAV systems to generate a DTM in relation to the vegetation cover (steppes and forests) and evaluate the performance of the system. Their research was conducted as per the following steps: (1) THE eBee platform with a zoom lens camera and EasyStar II with a fixed focal length camera were compared; (2) the UAV image was used to generate a DTM of the vegetation cover under leaf-off conditions; (3) it was evaluated as to whether an increase in the number of images could improve a lower-quality image; and (4) the DTM generated from the UAV image was compared with that produced via the Czech Republic's airborne laser scanning (ALS). In terms of point density and accuracy, EasyStar was able to achieve better results than eBee. The accuracy was improved after ground filtering in the point cloud for the forest environment with an RMSE of 0.11 (Easystar) and 0.13 (eBee) for each platform. However, the accuracy in the steppe environment was reduced slightly. Despite differences between the acquired point clouds, both systems were able to accurately detect terrain in open steppes and under the forest canopy in under leaf-off conditions with higher accuracy than a nationwide LiDAR-derived DTM [55].

Moudrý et al. [99] also evaluated the value of point clouds derived from aerial photogrammetry and LiDAR, to characterize post-mining sites. They acquired aerial images under leaf-off and leaf-on conditions. As a result, the point density of the point cloud under the leaf-off condition (an average density of 288 points per $\mathrm{m}^{2}$ ) was higher than under the leaf-on condition (an average density of 56 points per $\mathrm{m}^{2}$ ). Furthermore, it was observed to cover the study area uniformly. In addition, the accuracy of the DTM generated from the aerial photographs obtained under leaf-off conditions was similar to that of the DTM generated using LiDAR.

Padró et al. [100] presented an inexpensive convenient application that can monitor opencast mine restorations using UAS images. They performed field spectroradiometer measurements using a small drone equipped with a multispectral sensor to radiologically correct the UAS sensor data. The multispectral sensor used in this study has four spectral bands (green (530-570 nm), red $(640-680 \mathrm{~nm})$, red-edge $(730-740 \mathrm{~nm})$, and near infrared $(770-810 \mathrm{~nm}))$. In addition, images were processed to generate spectral information, vegetation and soil indices, structural information, and land cover maps. The generated spectral data and land cover classification helped to detect and quantify mine waste dumping, exposed soil, and other land cover extensions. In addition, they enabled the evaluation of plant formation and vegetation development, which, in turn, enabled a visual and intuitive comparison with the surrounding reference system.

Strohbach et al. [101] investigated the extent of vegetation restoration achieved via these rehabilitation measures, using high-resolution near infra-red aerial images combined with ground-based observations. 
Table 9 summarizes the reviewed literature on UAV applications for the monitoring of ecological restoration. Among the six reviewed studies, four applied fixed-wing UAVs and two used rotary-wing UAVs. The articles reviewed acquired digital camera images (four articles) and multispectral images (two articles). In terms of the targeted area scale, three papers were analyzed on the mine scale, two on the regional scale, and one on the zonal scale. Additionally, four articles were applied an the autonomous control type and two articles were unknown.

Table 9. Summary of UAV applications for monitoring of ecological restoration.

\begin{tabular}{|c|c|c|c|c|c|c|}
\hline Reference & Year & Aim of Study & UAV Type & $\begin{array}{l}\text { Acquisition } \\
\text { Data Type }\end{array}$ & $\begin{array}{c}\text { Target } \\
\text { Area Scale }\end{array}$ & Flying Control Style \\
\hline Lee et al. [96] & 2016 & $\begin{array}{l}\text { Analysis and monitoring of } \\
\text { changes in the ecological } \\
\text { restoration area using } \\
\text { UAS-based photogrammetry }\end{array}$ & Rotary wing & $\begin{array}{l}\text { Digital } \\
\text { camera } \\
\text { image }\end{array}$ & Mine scale & Unknown \\
\hline Urban et al. [97] & 2018 & $\begin{array}{l}\text { Comparison of aerial survey } \\
\text { results obtained with two } \\
\text { different UAVs }\end{array}$ & Fixed wing & $\begin{array}{l}\text { Digital } \\
\text { camera } \\
\text { image }\end{array}$ & $\begin{array}{l}\text { Regional } \\
\text { scale }\end{array}$ & Autonomous \\
\hline Moudrý et al. [98] & 2019 & $\begin{array}{l}\text { Creation of DTM related to } \\
\text { vegetation cover and } \\
\text { evaluation of UAV system } \\
\text { performance }\end{array}$ & Fixed wing & $\begin{array}{l}\text { Digital } \\
\text { camera } \\
\text { image }\end{array}$ & Mine scale & Autonomous \\
\hline Moudrý et al. [99] & 2019 & $\begin{array}{c}\text { Evaluation of point clouds } \\
\text { derived by aerial } \\
\text { photogrammetry LiDAR }\end{array}$ & Fixed wing & $\begin{array}{l}\text { Digital } \\
\text { camera } \\
\text { image }\end{array}$ & $\begin{array}{l}\text { Regional } \\
\text { scale }\end{array}$ & Autonomous \\
\hline Padró et al. [100] & 2019 & $\begin{array}{l}\text { Monitoring of mine } \\
\text { restorations using UAS images }\end{array}$ & Rotary wing & $\begin{array}{l}\text { Multispectral } \\
\text { image }\end{array}$ & Mine scale & Unknown \\
\hline Strohbach et al. [101] & 2018 & $\begin{array}{l}\text { Investigation of the extent of } \\
\text { vegetation establishment using } \\
\text { near infra-red aerial images }\end{array}$ & Fixed wing & $\begin{array}{l}\text { Multispectral } \\
\text { image }\end{array}$ & Zonal scale & Autonomous \\
\hline
\end{tabular}

\subsection{Monitoring of Ground Subsidence}

For safety reasons, it is highly challenging for humans to investigate and monitor areas where ground subsidence occurs. Therefore, the importance of using UAV to conveniently acquire data in areas that are difficult to access is increasing. In this study, the UAVs were applied to the tailings dams and subsidence areas that originated because of underground mining.

Suh and Choi [102] used UAV photogrammetry techniques to generate accurate and reliable subsidence inventory maps of abandoned mining areas. They set the Samsung limestone mine, located at Cheongwon-gun, Chungcheongbuk-do, Korea, as the research area and acquired aerial photographs using small drones. These photographs were processed with pre-installed GCPs information to generate geo-referenced orthoimages and DTMs. Thereby, sinkhole-type subsidence and its location information were identified. The area and volume could be calculated as shown in Figure 6. In addition, the generated DTM showed an error of approximately $14 \mathrm{~cm}$ during validation using the GCP locations. This was observed to be acceptable for subsidence mapping purposes.

(a)

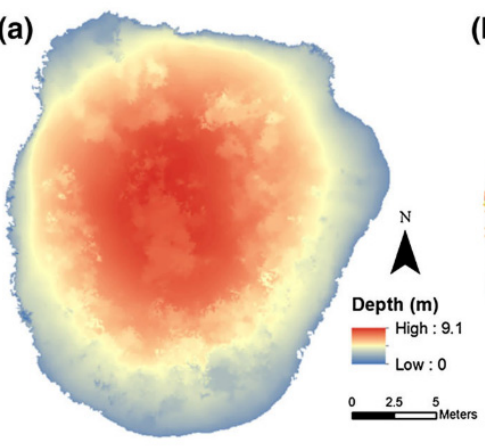

(b)

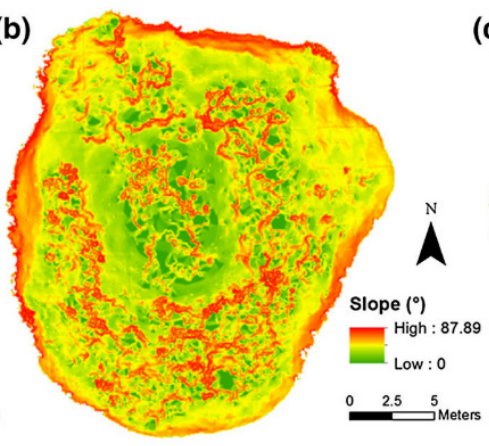

(c)

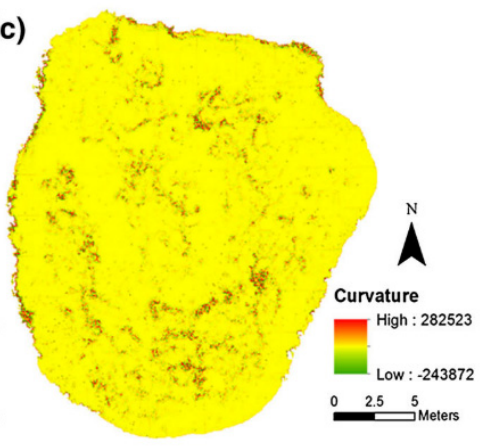

Figure 6. Topographic characteristics derived from a digital terrain model (DTM) of mining subsidence zones; (a) depth, (b) slope, and (c) curvature [102]. 
Rauhala et al. [103] used a UAV system to monitor the potential subsidence of tailings deposited in mines located in the sub-Arctic. They used SfM photogrammetry to generate an annual topographic model of the tailings surface, which tracked the displacement of the surface. Ground checkpoints investigated in a stable region of the impoundment were used to evaluate the accuracy of the model. An analysis revealed that the observed displacement of the surface was correlated with a combination of erosion, tailings settling, and compression of the peat layer underlying the tailings. Figure 7 shows a map and graph depicting the displacement of a surface developed via a combination of models generated at different times for a study area.
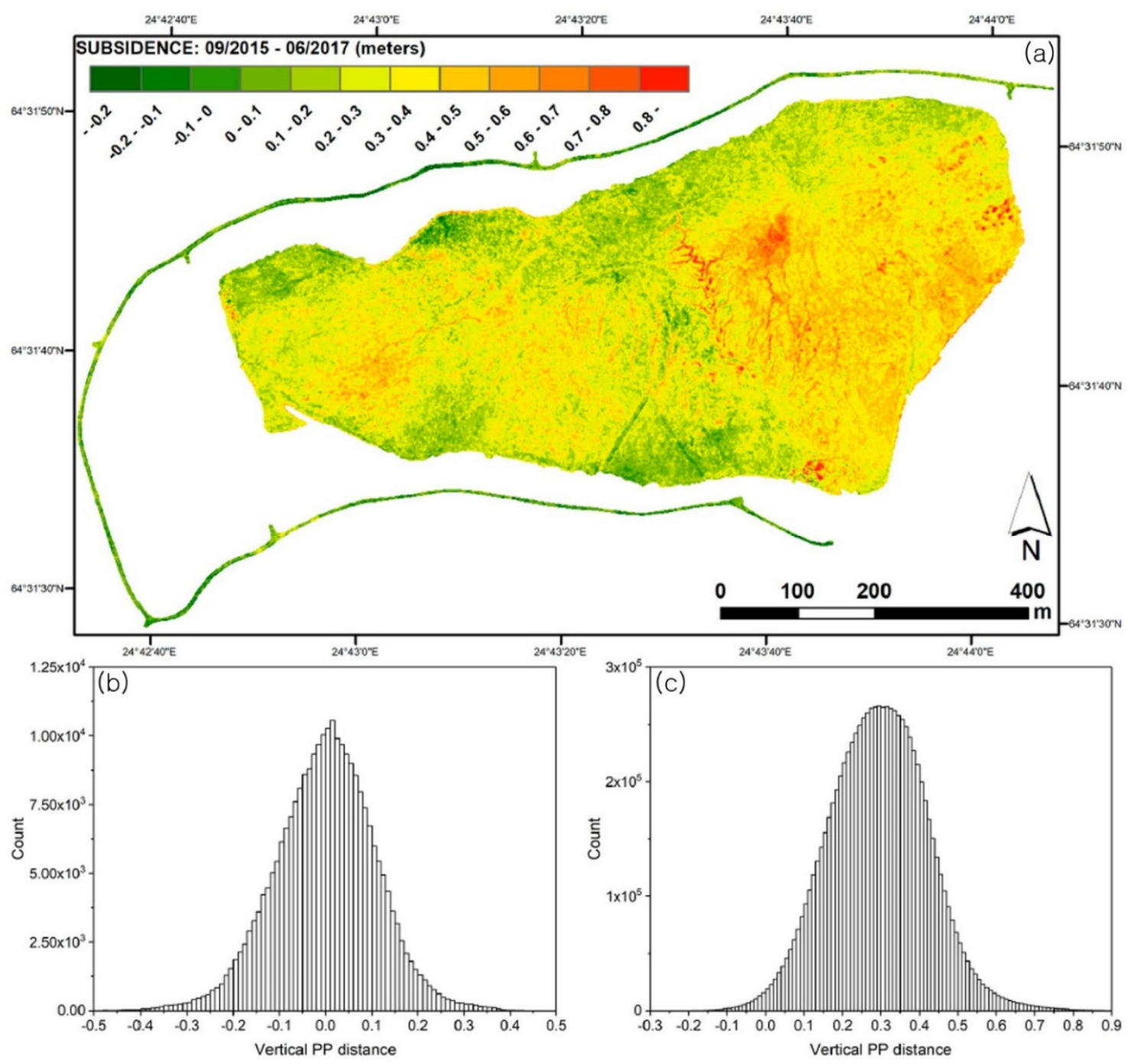

Figure 7. Potential subsidence of tailings. (a) Apparent subsidence between the June 2017 and August 2017 surveys, (b) distribution of point-to-point (PP) elevation differences in the service road, and (c) distribution of point-to-point elevation differences in the tailings surface between the June 2017 and August 2017 point clouds [103].

Dawei et al. [104] used UAV photogrammetry to monitor a surface dynamic subsidence basin (SDSB) generated as a result of underground coal mining and presented a method for obtaining parameters related to mining subsidence (PMS) in a short period of time. They acquired DEMs of two periods using a UAV, and developed an SDSB through subtraction of both the models. In addition, the PMS was obtained based on the dynamic inversion method.

Table 10 summarizes the reviewed literature on UAV applications to monitor ground subsidence. Among the three papers examined, two papers applied fixed-wing UAVs, and one paper used a 
rotary-wing UAV. All three studies acquired digital camera images for monitoring ground subsidence. As for the targeted area scale, two articles were analyzed on the zonal scale and one on the regional scale. Finally, one study used an autonomous flight mode and two were unknown.

Table 10. Summary of UAV applications for monitoring of ground subsidence.

\begin{tabular}{ccccccc}
\hline Reference & Year & Aim of Study & UAV Type & $\begin{array}{c}\text { Acquisition } \\
\text { Data Type }\end{array}$ & $\begin{array}{c}\text { Target } \\
\text { Area Scale }\end{array}$ & Flying Control Style \\
\hline Suh and Choi [102] & 2017 & $\begin{array}{c}\text { Generation of subsidence } \\
\text { inventory map using UAV } \\
\text { photogrammetry technology }\end{array}$ & Rotary wing & $\begin{array}{c}\text { Digital } \\
\text { camera } \\
\text { image }\end{array}$ & $\begin{array}{c}\text { Regional } \\
\text { scale }\end{array}$ & Autonomous \\
\hline Rauhala et al. [103] & 2017 & $\begin{array}{c}\text { Monitoring of potential } \\
\text { subsidence of tailings }\end{array}$ & Fixed wing & $\begin{array}{c}\text { Digital } \\
\text { camera } \\
\text { image }\end{array}$ & Zonal scale & Unknown \\
\hline Dawei et al. [104] & 2020 & $\begin{array}{c}\text { Monitoring of surface dynamic } \\
\text { subsidence basin caused by } \\
\text { underground mining }\end{array}$ & Fixed wing & $\begin{array}{c}\text { Digital } \\
\text { camera } \\
\text { image }\end{array}$ & Zonal scale & Unknown \\
\hline
\end{tabular}

\section{Discussion}

\subsection{Current Applications of UAVs in Mining}

In this paper, 65 research papers and MSC/PHD theses that encompassed a wide range of applications of UAVs within the mining domain were reviewed. From the review, tendencies that lead the classification of current UAV applications at the exploration, exploitation, and reclamation phases of the mining process were found, as follows:

(1) Geological and structural analysis via remote sensing at the exploration phase (seven papers);

(2) Airborne geophysical survey at the exploration phase (10 papers);

(3) Topographic surveying in open-pit mines at the exploitation phase (15 papers);

(4) Rock slope analysis at the exploitation phase (seven papers);

(5) Working environment analysis at the exploitation phase (six papers);

(6) Surveying in underground mines at the exploitation phase (seven papers);

(7) Soil and water pollution monitoring at the reclamation phase (four papers);

(8) Ecological restoration monitoring at the reclamation phase (six papers); and

(9) Ground subsidence monitoring at the reclamation phase (three papers).

Figure 8 shows the percentage distribution of each UAV application in mining and the number of studies classified under that application. UAV applications at the exploitation phase account for $53.8 \%$ of all reviewed studies. Topographic surveying in open-pit mines was the prevalent application at the exploitation phase. Applications of UAVs at the exploration and reclamation phases accounted for $26.2 \%$ and $20.0 \%$ of the reviewed studies, respectively. The airborne geophysical survey was the second most frequent application that used UAVs.

\subsection{Types of UAV Used in Mining}

From the review, the two types of UAVs used for various applications in mining of fixed-wing and rotary-wing were observed. Some studies used both. Table 11 displays the number of studies that used three types of UAV for each phase. Among the 65 studies, two with unknown types of UAVs used were excluded. The rotary wing was the prevalent type of UAV for applications at all mining process phases. Because rotary-wing UAVs can hover, takeoff, and land vertically, mainly applications in mining were used. Eleven studies dealing with UAV applications at the exploration (six papers), exploitation (four papers), and reclamation (one paper) phases used both fixed-wing and rotary-wing types to complement the strengths and weaknesses of each type. 


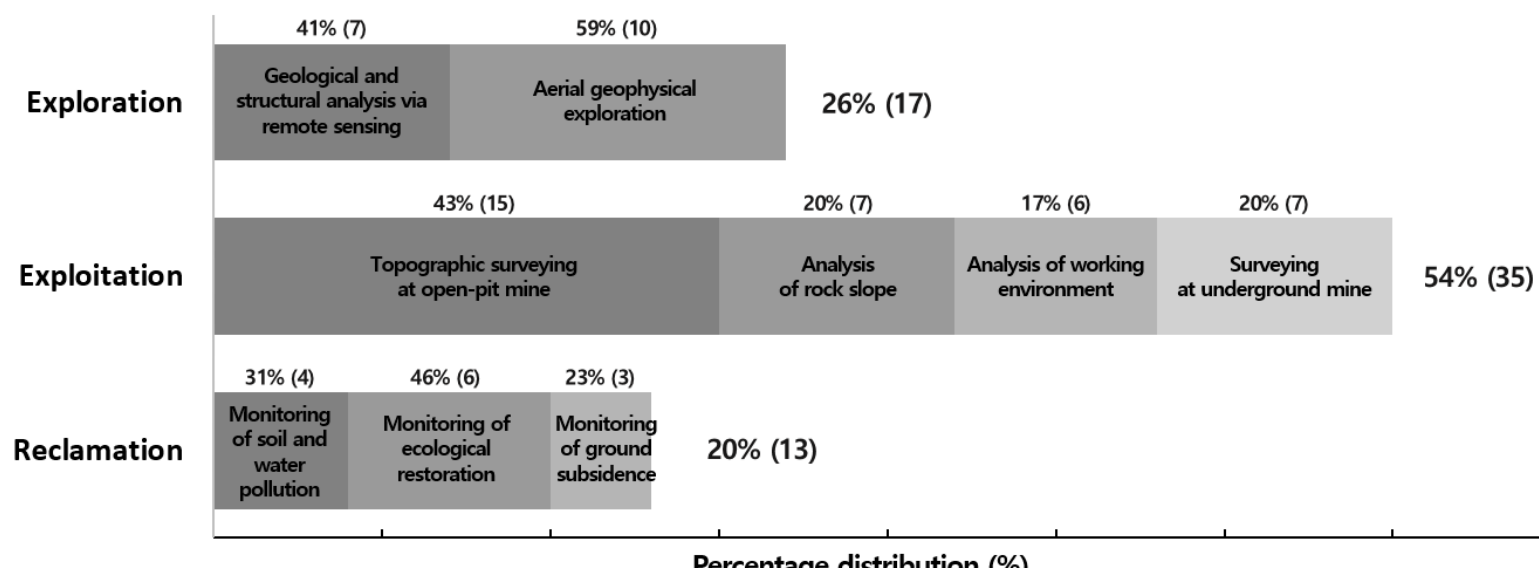

Figure 8. Percentage distribution and number of reviewed studies of UAV applications at the exploration, exploitation, and reclamation phases of the mining process.

Table 11. Numbers of reviewed studies by UAV types used at each phase of the mining process.

\begin{tabular}{ccccc}
\hline Type & Fixed Wing & Rotary Wing & Both & Sum \\
\hline Exploration & 1 & 10 & 6 & 17 \\
Exploitation & 5 & 25 & 4 & 34 \\
Reclamation & 6 & 5 & 1 & 12 \\
Sum & 12 & 40 & 11 & 63 \\
\hline
\end{tabular}

\subsection{Types of Data Acquired by Sensors for UAV Applications in Mining}

From 65 reviewed literature papers, six types of data acquired by sensors were found for UAV applications in mining as shown in Table 12. The sum of the acquired data presented in Table 12 is not 65 because two or more types of data were acquired by multiple sensors for UAV applications reported in seven literature papers $[43-45,55,89,91,95]$. Overall, the highest use was of images or videos captured by digital cameras (38 times), followed by geophysical data (14 times), and spectral and thermal images or data (13 times). The images or video captured by digital cameras were mainly used at the exploitation phase, and the use of geophysical data was relatively frequent at the exploration phase.

Table 12. Numbers of reviewed studies classified by acquired data types by sensors mounted on UAVs at each phase of the mining process.

\begin{tabular}{|c|c|c|c|c|}
\hline Phase & Exploration & Exploitation & Reclamation & Sum \\
\hline Image or video from digital camera & 3 & 28 & 7 & 38 \\
\hline $\begin{array}{l}\text { Multi- and hyperspectral, thermal } \\
\text { image or data }\end{array}$ & 6 & 3 & 4 & 13 \\
\hline Geophysics data & 13 & 0 & 1 & 14 \\
\hline Environmental monitoring data 1 & 0 & 1 & 1 & 2 \\
\hline Distance measuring data & 0 & 2 & 0 & 2 \\
\hline Etc. ${ }^{2}$ & 0 & 2 & 1 & 3 \\
\hline Sum & 22 & 36 & 14 & 72 \\
\hline
\end{tabular}

\footnotetext{
${ }^{1}$ data acquired by dust and temperature sensors mounted on UAVs; ${ }^{2}$ data acquired by IMU and network packet measurement sensors and water sampler mounted on UAVs.
}

\subsection{Scales of Target Area Selected for UAV Applications in Mining}

The 65 reviewed literature papers were grouped into three classes according to the scales of a target area of UAV applications at the exploration, exploitation, and reclamation phases. At the exploration phase, UAVs were used mainly for regional-scale studies (11 papers) involving mines and 
neighboring areas. However, at the exploitation phase, UAVs were observed to be mainly used for studies at the mine scale (18 papers) and zonal scale (16 papers), and the use of UAVs was observed to be insignificant for research at the regional scale (one paper). In the case of the reclamation phase, UAVs were used in similar proportions at all the scales: Regional scale (four papers), mine scale (three papers), and zonal scale (six papers).

\subsection{Styles of Flying Control Used for UAV Applications in Mining}

Among 65 reviewed studies, the style of flying control could be identified from 38 studies as manual, autonomous, or semi-autonomous. In other studies, the style was not reported. Table 13 illustrates three styles of flying control used for UAV applications at each phase of the mining process. The autonomous flight was commonly used at all phases (28 papers), followed by the semi-autonomous flight (eight papers). A manual style of operation was only reported from two papers that describe UAV applications at the exploration phase.

Table 13. Numbers of reviewed literature papers by the flying control style of UAVs used at each phase of the mining process.

\begin{tabular}{ccccc}
\hline Style & Manual & Autonomous & Semi-Autonomous & Sum \\
\hline Exploration & 0 & 8 & 3 & 11 \\
Exploitation & 2 & 13 & 5 & 20 \\
Reclamation & 0 & 7 & 0 & 7 \\
Sum & 2 & 28 & 8 & 38 \\
\hline
\end{tabular}

\section{Conclusions}

This review provided an analysis of studies conducted in the past 10 years by academics, for using UAV technology in the mining process that proceeds through the exploration, exploitation, and reclamation phases. A total of 65 research papers published in academic journals and MSC/PHD theses were identified, and their detailed contents on the use of UAVs were analyzed for systematic reviews. These reviews found that current applications of UAVs in mining can be categorized into (1) geological and structural analysis via remote sensing, (2) aerial geophysical survey at the exploration phase, (3) topographic surveying in open-pit mines, (4) rock slope analysis, (5) working environment analysis, (6) surveying in underground mines at the exploitation phase, (7) soil and water pollution monitoring, (8) ecological restoration monitoring, and (9) ground subsidence monitoring at the reclamation phase. Among the current applications, topographic surveying in open-pit mines has been applied the most. The most common types of UAVs and data acquired by sensors for UAV applications in mining were the rotary wing and images or video captured by digital cameras, respectively. Regarding the scales of the target area for UAV applications, regional-scale studies were usually conducted at the exploration phase. However, mine and zonal scale studies were more prevalent at the exploitation phase. An autonomous style of flying control was commonly used for UAV applications at all phases of the mining process.

On considering the studies that applied UAVs in the mining field, it has been observed that UAVs present the advantages of being operable and manageable at a low cost, the ability to work in areas difficult to access by people and other equipment, and the ability to acquire data relatively quickly. Compared to a manned airborne survey, the UAV-based survey can acquire high-resolution data with high density because UAVs can fly at low altitudes. In addition, easily controlling and maneuvering UAVs with only minimal training is an advantage. Therefore, UAVs are actively used for mine development tasks, such as aerial surveying, airborne geophysical exploration, and environmental monitoring.

The UAVs also have disadvantages, such as a low payload capacity, low fuel, and energy efficiency, short flight times, and dependence on weather conditions. Because of the low payload capacity of the UAVs, there is a limit to the number of sensors that can be mounted on the UAVs. As with 
airborne survey, sudden weather changes in the field can incur additional costs for the investigation. In addition, since the amount of data acquired in the UAV-based survey was massive, maintaining sufficient hardware and software to process it is necessary. If these disadvantages are overcome, UAVs will be more widely applied in the mining industry.

Author Contributions: Conceptualization, Y.C.; methodology, Y.C.; software, S.P.; validation, S.P.; formal analysis, S.P.; investigation, Y.C.; resources, Y.C.; data curation, S.P.; writing-original draft preparation, S.P. and Y.C.; writing-review and editing, Y.C.; visualization, S.P.; supervision, Y.C.; project administration, Y.C.; funding acquisition, Y.C. All authors have read and agreed to the published version of the manuscript.

Funding: This work was supported by the KETEP grant funded by the Korea Government's Ministry of Trade, Industry and Energy (project no. 20182510102370).

Conflicts of Interest: The authors declare no conflict of interest.

\section{References}

1. Liu, P.; Chen, A.Y.; Huang, Y.N.; Han, J.Y.; Lai, J.S.; Kang, S.C.; Wu, T.H.; Wen, M.C.; Tsai, M.H. A review of rotorcraft unmanned aerial vehicle (UAV) developments and applications in civil engineering. Smart Struct. Syst. 2014, 13, 1065-1094. [CrossRef]

2. De Melo, R.R.S.; Costa, D.B.; Álvares, J.S.; Irizarry, J. Applicability of unmanned aerial system (UAS) for safety inspection on construction sites. Saf. Sci. 2017, 98, 174-185. [CrossRef]

3. Greenwood, W.W.; Lynch, J.P.; Zekkos, D. Applications of UAVs in civil infrastructure. J. Infrastruct. Syst. 2019, 25, 04019002. [CrossRef]

4. Irizarry, J.; Costa, D.B. Exploratory study of potential applications of unmanned aerial systems for construction management tasks. J. Manag. Eng. 2016, 32, 05016001. [CrossRef]

5. Gheisari, M.; Irizarry, J.; Walker, B.N. UAS4SAFETY: The Potential of Unmanned Aerial Systems for Construction Safety Applications. In Proceedings of the 2014 Construction Research Congress: Construction in a Global Network, Atlanta, GA, USA, 19-21 May 2014; pp. 1801-1810.

6. Zhou, S.; Gheisari, M. Unmanned aerial system applications in construction: A systematic review. Constr. Innov. 2018, 18, 453-468. [CrossRef]

7. Gheisari, M.; Esmaeili, B. Unmanned Aerial Systems (UAS) for Construction Safety Applications. In Proceedings of the 2016 Construction Research Congress: Old and New Construction Technologies Converge in Historic San Juan, San Juan, Puerto Rico, 31 May-2 June 2016; pp. 2642-2650.

8. Barmpounakis, E.N.; Vlahogianni, E.I.; Golias, J.C. Unmanned Aerial Aircraft Systems for transportation engineering: Current practice and future challenges. Int. J. Transp. Sci. Technol. 2016, 5, 111-122. [CrossRef]

9. Barbedo, J.G.A. A Review on the Use of Unmanned Aerial Vehicles and Imaging Sensors for Monitoring and Assessing Plant Stresses. Drones 2019, 3, 40. [CrossRef]

10. Tsouros, D.C.; Bibi, S.; Sarigiannidis, P.G. A review on UAV-based applications for precision agriculture. Information 2019, 10, 349. [CrossRef]

11. Unal, I.; Topakci, M. A Review on Using Drones for Precision Farming Applications. In Proceedings of the 12th International Congress on Agricultural Mechanization and Energy, Cappadocia, Turkey, 3-6 September 2014; pp. 276-283.

12. Mogili, U.R.; Deepak, B.B.V.L. Review on application of drone systems in precision agriculture. Procedia Comput. Sci. 2018, 133, 502-509. [CrossRef]

13. Pádua, L.; Vanko, J.; Hruška, J.; Adão, T.; Sousa, J.J.; Peres, E.; Morais, R. UAS, sensors, and data processing in agroforestry: A review towards practical applications. Int. J. Remote Sens. 2017, 38, 2349-2391. [CrossRef]

14. Hassler, S.C.; Baysal-Gurel, F. Unmanned Aircraft System (UAS) Technology and Applications in Agriculture. Agronomy 2019, 9, 618. [CrossRef]

15. Villa, T.F.; Gonzalez, F.; Miljievic, B.; Ristovski, Z.D.; Morawska, L. An overview of small unmanned aerial vehicles for air quality measurements: Present applications and future prospectives. Sensors 2016, 16, 1072. [CrossRef]

16. Goodbody, T.R.; Coops, N.C.; Marshall, P.L.; Tompalski, P.; Crawford, P. Unmanned aerial systems for precision forest inventory purposes: A review and case study. For. Chron. 2017, 93, 71-81. [CrossRef] 
17. Torresan, C.; Berton, A.; Carotenuto, F.; Di Gennaro, S.F.; Gioli, B.; Matese, A.; Miglietta, F.; Vagnoli, C.; Zaldei, A.; Wallace, L.; et al. Forestry applications of UAVs in Europe: A review. Int. J. Remote Sens. 2017, 38, 2427-2447. [CrossRef]

18. Manfreda, S.; McCabe, M.F.; Miller, P.E.; Lucas, R.; Pajuelo Madrigal, V.; Mallinis, G.; Ben Dor, E.; Helman, D.; Estes, L.; Ciraolo, G.; et al. On the use of unmanned aerial systems for environmental monitoring. Remote Sens. 2018, 10, 641. [CrossRef]

19. Linchant, J.; Lisein, J.; Semeki, J.; Lejeune, P.; Vermeulen, C. Are unmanned aircraft systems (UAS s) the future of wildlife monitoring? A review of accomplishments and challenges. Mammal Rev. 2019, 45, $239-252$. [CrossRef]

20. Wang, D.; Shao, Q.; Yue, H. Surveying Wild Animals from Satellites, Manned Aircraft and Unmanned Aerial Systems (UAS s): A Review. Remote Sens. 2019, 11, 1308. [CrossRef]

21. Rees, A.F.; Avens, L.; Ballorain, K.; Bevan, E.; Broderick, A.C.; Carthy, R.R.; Christianen, M.J.A.; Duclos, G.; Heithaus, M.R.; Johnston, D.W.; et al. The potential of unmanned aerial systems for sea turtle research and conservation: A review and future directions. Endanger. Species Res. 2018, 35, 81-100. [CrossRef]

22. Rhee, D.S.; Kim, Y.D.; Kang, B.; Kim, D. Applications of unmanned aerial vehicles in fluvial remote sensing: An overview of recent achievements. KSCE J. Civ. Eng. 2018, 22, 588-602. [CrossRef]

23. Klemas, V.V. Coastal and environmental remote sensing from unmanned aerial vehicles: An overview. J. Coast. Res. 2015, 31, 1260-1267. [CrossRef]

24. Bryson, M.; Williams, S. Review of Unmanned Aerial Systems (UAS) for Marine Surveys; Australian Centre for Field Robotics, University of Sydney: Sydney, Australia, 2015.

25. Kislik, C.; Dronova, I.; Kelly, M. UAVs in support of algal bloom research: A review of current applications and future opportunities. Drones 2018, 2, 35. [CrossRef]

26. Bravo, R.; Leiras, A. Literature Review of the Application of UAVs in Humanitarian Relief. In Proceedings of the XXXV Encontro Nacional de Engenharia de Producao, Fortaleza, Brazil, 13-16 October 2015.

27. Yuan, C.; Zhang, Y.; Liu, Z. A survey on technologies for automatic forest fire monitoring, detection, and fighting using unmanned aerial vehicles and remote sensing techniques. Can. J. Res. 2015, 45, 783-792. [CrossRef]

28. Saleem, Y.; Rehmani, M.H.; Zeadally, S. Integration of cognitive radio technology with unmanned aerial vehicles: Issues, opportunities, and future research challenges. J. Netw. Comput. Appl. 2015, 50, 15-31. [CrossRef]

29. Zeng, Y.; Zhang, R.; Lim, T.J. Wireless communications with unmanned aerial vehicles: Opportunities and challenges. IEEE Commun. Mag. 2016, 54, 36-42. [CrossRef]

30. Rosser, J.C., Jr.; Vignesh, V.; Terwilliger, B.A.; Parker, B.C. Surgical and medical applications of drones: A comprehensive review. JSLS 2018, 22, e2018.00018. [CrossRef]

31. Hustrulid, W.A.; Kuchta, M.; Martin, R.K. Open Pit Mine Planning and Design, 3rd ed.; CRC Press: Leiden, the Netherlands, 2013; pp. 1-1288. ISBN 978-1-4822-2117-6.

32. Choi, Y.; Baek, J.; Park, S. Review of GIS-Based Applications for Mining: Planning, Operation, and Environmental Management. Appl. Sci. 2020, 10, 2266. [CrossRef]

33. Cress, J.J.; Hutt, M.; Sloan, J.; Bauer, M.; Feller, M.; Goplen, S. Us Geological Survey Unmanned Aircraft Systems (UAS) Roadmap 2014; US Department of the Interior, US Geological Survey: Reston, VA, USA, 2015.

34. Lee, S.; Choi, Y. Reviews of unmanned aerial vehicle (drone) technology trends and its applications in the mining industry. Geosystem Eng. 2016, 19, 197-204. [CrossRef]

35. Paisiriyuenyong, M.P. Unmanned Aerial Vehicle (UAV) Technology in Thailand, and Applying Marketing in the Mining Industry. Ph.D. Thesis, Thammasat University, Bangkok, Thailand, 2016.

36. Ren, H.; Zhao, Y.; Xiao, W.; Hu, Z. A review of UAV monitoring in mining areas: Current status and future perspectives. Int. J. Coal Sci. Technol. 2019, 6, 1-14. [CrossRef]

37. Buczyńska, A. Remote sensing and GIS technologies in land reclamation and landscape planning processes on post-mining areas in the Polish and world literature. AIP Conf. Proc. 2020, 2209, 04002. [CrossRef]

38. Dering, G.M.; Micklethwaite, S.; Thiele, S.T.; Vollgger, S.A.; Cruden, A.R. Review of drones, photogrammetry and emerging sensor technology for the study of dykes: Best practises and future potential. J. Volcanol. Geotherm. Res. 2019, 373, 148-166. [CrossRef] 
39. Madjid, M.Y.A.; Vandeginste, V.; Hampson, G.; Jordan, C.J.; Booth, A.D. Drones in carbonate geology: Opportunities and challenges, and application in diagenetic dolomite geobody mapping. Mar. Pet. Geol. 2018, 91, 723-734. [CrossRef]

40. Beretta, F.; Rodrigues, A.L.; Peroni, R.L.; Costa, J.F.C.L. Automated lithological classification using UAV and machine learning on an open cast mine. Appl. Earth Sci. 2019, 128, 79-88. [CrossRef]

41. Jakob, S.; Zimmermann, R.; Gloaguen, R. Processing of Drone-Borne Hyperspectral Data for Geological Applications. In Proceedings of the 2016 8th Workshop on Hyperspectral Image and Signal Processing: Evolution in Remote Sensing (WHISPERS), Los Angeles, CA, USA, 21-24 August 2016; pp. 1-5. [CrossRef]

42. Jakob, S.; Zimmermann, R.; Gloaguen, R. The need for accurate geometric and radiometric corrections of drone-borne hyperspectral data for mineral exploration: Mephysto-A toolbox for pre-processing drone-borne hyperspectral data. Remote Sens. 2017, 9, 88. [CrossRef]

43. Kirsch, M.; Lorenz, S.; Zimmermann, R.; Tusa, L.; Möckel, R.; Hödl, P.; Booysen, R.; Khodadadzadeh, M.; Gloaguen, R. Integration of terrestrial and drone-borne hyperspectral and photogrammetric sensing methods for exploration mapping and mining monitoring. Remote Sens. 2018, 10, 1366. [CrossRef]

44. Heincke, B.; Jackisch, R.; Saartenoja, A.; Salmirinne, H.; Rapp, S.; Zimmermann, R.; Pirttijärvi, M.; Sörensen, E.V.; Gloaguen, R.; Ek, L.; et al. Developing multi-sensor drones for geological mapping and mineral exploration: Setup and first results from the MULSEDRO project. Geol. Surv. Den. Greenl. Bull. 2019, 43, e2019430302. [CrossRef]

45. Jackisch, R.; Madriz, Y.; Zimmermann, R.; Pirttijärvi, M.; Saartenoja, A.; Heincke, B.H.; Salmirinne, H.; Kujasalo, J.-P.; Andreani, L.; Gloaguen, R.; et al. Drone-Borne Hyperspectral and Magnetic Data Integration: Otanmäki Fe-Ti-V Deposit in Finland. Remote Sens. 2019, 11, 2084. [CrossRef]

46. Malehmir, A.; Dynesius, L.; Paulusson, K.; Paulusson, A.; Johansson, H.; Bastani, M.; Wedmark, P.; Marsden, P. The potential of rotary-wing UAV-based magnetic surveys for mineral exploration: A case study from central Sweden. Lead. Edge 2017, 36, 552-557. [CrossRef]

47. Eck, C.; Imbach, B. Aerial magnetic sensing with an UAV helicopter. Int. Arch. Photogramm. Remote Sens. Spat. Inf. Sci. 2011, 38, 81-85. [CrossRef]

48. Stoll, J.; Moritz, D. Unmanned Aircraft Systems for Rapid Near Surface Geophysical Measurements. In Proceedings of the 75th EAGE Conference \& Exhibition-Workshops, London, UK, 10-13 June 2013; European Association of Geoscientists \& Engineers: Houten, the Netherlands; p. cp-349-00062. [CrossRef]

49. Parshin, A.V.; Morozov, V.A.; Blinov, A.V.; Kosterev, A.N.; Budyak, A.E. Low-altitude geophysical magnetic prospecting based on multirotor UAV as a promising replacement for traditional ground survey. Geo-Spat. Inf. Sci. 2018, 21, 67-74. [CrossRef]

50. Azpúrua, H.; Potje, G.A.; Rezeck, P.A.; Freitas, G.M.; Uzeda Garcia, L.G.; Nascimento, E.R.; Macharet, D.G.; Campos, M.F. Cooperative digital magnetic-elevation maps by small autonomous aerial robots. J. Field Robot. 2019, 36, 1378-1398. [CrossRef]

51. Walter, C.; Braun, A.; Fotopoulos, G. High-resolution unmanned aerial vehicle aeromagnetic surveys for mineral exploration targets. Geophys. Prospect. 2020, 68, 334-349. [CrossRef]

52. Parvar, K.; Braun, A.; Layton-Matthews, D.; Burns, M. UAV magnetometry for chromite exploration in the Samail ophiolite sequence, Oman. J. Unmanned Veh. Syst. 2017, 6, 57-69. [CrossRef]

53. Cunningham, M.; Samson, C.; Wood, A.; Cook, I. Aeromagnetic surveying with a rotary-wing unmanned aircraft system: A case study from a zinc deposit in Nash Creek, New Brunswick, Canada. Pure Appl. Geophys. 2018, 175, 3145-3158. [CrossRef]

54. Parshin, A.; Grebenkin, N.; Morozov, V.; Shikalenko, F. Research Note: First results of a low-altitude unmanned aircraft system gamma survey by comparison with the terrestrial and aerial gamma survey data. Geophys. Prospect. 2018, 66, 1433-1438. [CrossRef]

55. Li, W.J.; Qin, X.W.; Gan, X.P. The IGGE UAV Aero Magnetic and Radiometric Survey System. In Near Surface Geoscience 2014, Proceedings of the 20th European Meeting of Environmental and Engineering Geophysics, Athens, Greece, 14-18 September 2014; European Association of Geoscientists \& Engineers: Houten, the Netherlands, 2014.

56. Wang, Q.; Wu, L.; Chen, S.; Shu, D.; Xu, Z.; Li, F.; Wang, R. Accuracy evaluation of 3D geometry from low-attitude UAV images: A case study at zijin mine. Int. Arch. Photogramm. Remote Sens. Spat. Inf. Sci. 2014, 40, 297-300. [CrossRef]

57. Cho, S.J.; Bang, E.S.; Kang, I.M. Construction of precise digital terrain model for nonmetal open-pit mine by using unmanned aerial photograph. Econ. Env. Geol. 2015, 48, 205-212. [CrossRef] 
58. Lee, S.; Choi, Y. Topographic survey at small-scale open-pit mines using a popular rotary-wing unmanned aerial vehicle (drone). Tunn. Undergr. Space 2015, 25, 462-469. [CrossRef]

59. Lee, S.; Choi, Y. On-site demonstration of topographic surveying techniques at open-pit mines using a fixed-wing unmanned aerial vehicle (drone). Tunn. Undergr. Space 2015, 25, 462-468. [CrossRef]

60. Lee, S.; Choi, Y. Comparison of topographic surveying results using a fixed-wing and a popular rotary-wing unmanned aerial vehicle (drone). Tunn. Undergr. Space 2016, 26, 24-31. [CrossRef]

61. Chen, J.; Li, K.; Chang, K.J.; Sofia, G.; Tarolli, P. Open-pit mining geomorphic feature characterisation. Int. J. Appl. Earth Obs. Geoinf. 2016, 42, 76-86. [CrossRef]

62. Sofia, G.; Mariniello, F.; Tarolli, P. A new landscape metric for the identification of terraced sites: The slope local length of auto-correlation (SLLAC). ISPRS J. Photogramm. Remote Sens. 2014, 96, 123-133. [CrossRef]

63. Rossi, P.; Mancini, F.; Dubbini, M.; Mazzone, F.; Capra, A. Combining nadir and oblique UAV imagery to reconstruct quarry topography: Methodology and feasibility analysis. Eur. J. Remote. Sens. 2017, 50, $211-221$. [CrossRef]

64. Chirico, P.G.; DeWitt, J.D. Mapping informal small-scale mining features in a data-sparse tropical environment with a small UAS. J. Unmanned Veh. Syst. 2017, 5, 69-91. [CrossRef]

65. Gil, M.; Frackiewicz, P. Optimization of the Location of Observation Network Points in Open-Pit Mining's. In Proceedings of the 26th Geographic Information Systems Conference and Exhibition "GIS ODYSSEY 2019", Split, Croatia, 2-6 September 2019; Croatian Information Technology Society-GIS Forum: Zagreb, Croatia, 2019; pp. 73-80.

66. Tscharf, A.; Rumpler, M.; Fraundorfer, F.; Mayer, G.; Bischof, H. On the Use of UAV s in Mining and Archaeology-Geo-Accurate 3d Reconstructions Using Various Platforms and Terrestrial Views. ISPRS Ann. Photogramm. Remote Sens. Spat. Inf. Sci. 2015, 2, 15-22. [CrossRef]

67. Xiang, J.; Chen, J.; Sofia, G.; Tian, Y.; Tarolli, P. Open-pit mine geomorphic changes analysis using multi-temporal UAV survey. Environ. Earth Sci. 2018, 77, 220. [CrossRef]

68. Beretta, F.; Shibata, H.; Cordova, R.; Peroni, R.D.L.; Azambuja, J.; Costa, J.F.C.L. Topographic modelling using UAVs compared with traditional survey methods in mining. REM-Int. Eng. J. 2018, 71, 463-470. [CrossRef]

69. Kršák, B.; Blišt'an, P.; Pauliková, A.; Puškárová, P.; Kovanič, L'.; Palková, J.; Zelizňaková, V. Use of low-cost UAV photogrammetry to analyze the accuracy of a digital elevation model in a case study. Measurement 2016, 91, 276-287. [CrossRef]

70. Ge, L.; Li, X.; Ng, A.H.M. UAV for Mining Applications: A Case Study at an Open-Cut Mine and a Longwall Mine in New South Wales, Australia. In Proceedings of the 2016 IEEE International Geoscience and Remote Sensing Symposium (IGARSS), Beijing, China, 10-15 July 2016; IEEE: Piscataway, NJ, USA, 2016; pp. 5422-5425. [CrossRef]

71. Esposito, G.; Mastrorocco, G.; Salvini, R.; Oliveti, M.; Starita, P. Application of UAV photogrammetry for the multi-temporal estimation of surface extent and volumetric excavation in the Sa Pigada Bianca open-pit mine, Sardinia, Italy. Environ. Earth Sci. 2017, 76, 103. [CrossRef]

72. McLeod, T.K. 3D Imaging Applications in Earth Sciences Using Video Data Acquired from an Unmanned Aerial Vehicle. Ph.D. Thesis, Carleton University, Ottawa, ON, Canada, 2012.

73. McLeod, T.; Samson, C.; Labrie, M.; Shehata, K.; Mah, J.; Lai, P.; Wang, L.; Elder, J.H. Using video acquired from an unmanned aerial vehicle (UAV) to measure fracture orientation in an open-pit mine. Geomatica 2013, 67, 173-180. [CrossRef]

74. Vrublová, D.; Kapica, R.; Jiránková, E.; Struś, A. Documentation of landslides and inaccessible parts of a mine using an unmanned UAV system and methods of digital terrestrial photogrammetry. Geosci. Eng. 2015, 61, 8-19. [CrossRef]

75. Blistan, P.; Kovanič, L'.; Zelizňaková, V.; Palková, J. Using UAV photogrammetry to document rock outcrops. Acta Montan. Slovaca 2016, 21, 154-161.

76. Beretta, F.; Rodrigues, Á.L.; Peroni, R.D.L.; Costa, J.F.C.L. Using UAV for automatic lithological classification of open pit mining front. REM-Int. Eng. J. 2019, 72, 17-23. [CrossRef]

77. Katuruza, M.; Birch, C. The use of unmanned aircraft system technology for highwall mapping at Isibonelo Colliery, South Africa. J. S. Afr. Inst. Min. Metall. 2019, 119, 291-295. [CrossRef]

78. Stead, D.; Donati, D.; Wolter, A.; Sturzenegger, M. Application of Remote Sensing to the Investigation of Rock Slopes: Experience Gained and Lessons Learned. ISPRS Int. J. Geoinf. 2019, 7, 296. [CrossRef] 
79. Alvarado, M.; Gonzalez, F.; Fletcher, A.; Doshi, A. Towards the development of a low cost airborne sensing system to monitor dust particles after blasting at open-pit mine sites. Sensors 2015, 15, 19667-19687. [CrossRef]

80. Bamford, T.; Esmaeili, K.; Schoellig, A.P. A real-time analysis of post-blast rock fragmentation using UAV technology. Int. J. Min. Reclam. Environ. 2017, 31, 439-456. [CrossRef]

81. Bamford, T.; Esmaeili, K.; Schoellig, A.P. Aerial Rock Fragmentation Analysis in Low-Light Condition Using UAV Technology. In Proceedings of the 38th Application of Computers and Operation Research in the Mineral Industry, Golden, CO, USA, 9-11 August 2017.

82. Motepe, S. Software Integration for Human Detection in Mining UAV Systems. Master's Thesis, University of KwaZulu Natal, Durban, South Africa, 2013.

83. Péter, H.; László, D.; János, V.P. Civilian Use of Drones in the Life of Mining Rescue Helicopters. In Proceedings of the 2016 IEEE 17th International Symposium on Computational Intelligence and Informatics (CINTI), Budapest, Hungary, 17-19 November 2016; pp. 299-302. [CrossRef]

84. Ranjan, A.; Panigrahi, B.; Sahu, H.B.; Misra, P. SkyHelp: UAV Assisted Emergency Communication in Deep Open Pit Mines. In Proceedings of the 1st International Workshop on Internet of People, Assistive Robots and Things, Munich, Germany, 10 June 2018; pp. 31-36.

85. Turner, R.M.; Bhagwat, N.P.; Galayda, L.J.; Knoll, C.S.; Russell, E.A.; MacLaughlin, M.M. Geotechnical Characterization of Underground Mine Excavations from UAV-Captured Photogrammetric \& Thermal Imagery. In Proceedings of the ARMA 2018: 52nd US Rock Mechanics/Geomechanics Symposium, Seattle, WA, USA, 17-20 June 2018.

86. Kanellakis, C.; Nikolakopoulos, G. Evaluation of Visual Localization Systems in Underground Mining. In Proceedings of the 2016 24th Mediterranean Conference on Control and Automation (MED), Athens, Greece, 21-24 June 2016; pp. 539-544.

87. Freire, G.R.; Cota, R.F. Capture of Images in Inaccessible Areas in an Underground Mine Using an Unmanned Aerial Vehicle. In Proceedings of the First International Conference on Underground Mining Technology, Sudbury, ON, Canada, 11-13 October 2017; Australian Centre for Geomechanics: Crawley, Australia, 2017.

88. Raj, P. Use of Drones in an Underground Mine for Geotechnical Monitoring. Master's. Thesis, the University of Arizona, Phoenix, AZ, USA, 2019.

89. Turner, R.M.; MacLaughlin, M.M.; Iverson, S.R. Identifying and mapping potentially adverse discontinuities in underground excavations using thermal and multispectral UAV imagery. Eng. Geol. 2020, 266, 105470. [CrossRef]

90. Mitchell, J.; Marshall, J.A. Design of a Novel Auto-Rotating UAV Platform for Underground Mine Cavity Surveying. 2017. Available online: http://hdl.handle.net/1974/15277 (accessed on 4 April 2020).

91. Azhari, F.; Kiely, S.; Sennersten, C.; Lindley, C.; Matuszak, M.; Hogwood, S. A Comparison of Sensors for Underground Void Mapping by Unmanned Aerial Vehicles. In Proceedings of the First International Conference on Underground Mining Technology, Sudbury, ON, Canada, 11-13 October 2017; Australian Centre for Geomechanics: Crawley, Australia, 2017; pp. 419-430.

92. Martin, P.G.; Payton, O.D.; Fardoulis, J.S.; Richards, D.A.; Scott, T.B. The use of unmanned aerial systems for the mapping of legacy uranium mines. J. Environ. Radioact. 2015, 143, 135-140. [CrossRef]

93. Fang, Y.; Hu, Z.; Xu, L.; Wong, A.; Clausi, D.A. Estimation of Iron Concentration in Soil of a Mining Area from UAV-Based Hyperspectral Imagery. In Proceedings of the 2019 10th Workshop on Hyperspectral Imaging and Signal Processing: Evolution in Remote Sensing (WHISPERS), Amsterdam, the Netherlands, 24-26 September 2019; pp. 1-5. [CrossRef]

94. Jackisch, R.; Lorenz, S.; Zimmermann, R.; Möckel, R.; Gloaguen, R. Drone-borne hyperspectral monitoring of acid mine drainage: An example from the Sokolov Lignite District. Remote Sens. 2018, 10, 385. [CrossRef]

95. Castendyk, D.N.; Straight, B.J.; Voorhis, J.C.; Somogyi, M.K.; Jepson, W.E.; Kucera, B.L. Using Aerial Drones to Select Sample Depths in Pit Lakes. In Proceedings of the 13th International Conference on Mine Closure, Australian Centre for Geomechanics, Perth, Australia, 2-5 September 2019; pp. 1113-1126. [CrossRef]

96. Lee, D.G.; Yu, Y.G.; Ru, J.H.; Lee, H.J. Change monitoring in ecological restoration area of open-pit mine using drone photogrammetry. J. Korean Soc. Geospat. Inf. Syst. 2016, 24, 97-104. [CrossRef]

97. Urban, R.; Štroner, M.; Křemen, T.; Braun, J.; Moeser, M. A novel approach to estimate systematic and random error of terrain derived from UAV s: A case study from a post-mining site. Acta Montan. Slovaca 2018, 23, 325-336. 
98. Moudrý, V.; Urban, R.; Štroner, M.; Komárek, J.; Brouček, J.; Prošek, J. Comparison of a commercial and home-assembled fixed-wing UAV for terrain mapping of a post-mining site under leaf-off conditions. Int. J. Remote Sens. 2019, 40, 555-572. [CrossRef]

99. Moudrý, V.; Gdulová, K.; Fogl, M.; Klápště, P.; Urban, R.; Komárek, J.; Moudrá, L.; Štroner, M.; Barták, V.; Solský, M.; et al. Comparison of leaf-off and leaf-on combined UAV imagery and airborne LiDAR for assessment of a post-mining site terrain and vegetation structure: Prospects for monitoring hazards and restoration success. Appl. Geogr. 2019, 104, 32-41. [CrossRef]

100. Padró, J.C.; Carabassa, V.; Balagué, J.; Brotons, L.; Alcañiz, J.M.; Pons, X. Monitoring opencast mine restorations using Unmanned Aerial System (UAS) imagery. Sci. Total Environ. 2019, 657, 1602-1614. [CrossRef]

101. Strohbach, B.J.; Hauptfleisch, M.L.; Green-Chituti, A.; Diener, S.M. Determining rehabilitation effectiveness at the Otjikoto Gold Mine, Otjozondjupa Region, Namibia, using high-resolution NIR aerial imagery. Namib. J. Environ. 2018, 2, 134-146.

102. Suh, J.; Choi, Y. Mapping hazardous mining-induced sinkhole subsidence using unmanned aerial vehicle (drone) photogrammetry. Environ. Earth Sci. 2017, 76, 144. [CrossRef]

103. Rauhala, A.; Tuomela, A.; Davids, C.; Rossi, P.M. UAV remote sensing surveillance of a mine tailings impoundment in Sub-Arctic conditions. Remote Sens. 2017, 9, 1318. [CrossRef]

104. Dawei, Z.; Lizhuang, Q.; Demin, Z.; Baohui, Z.; Lianglin, G. Unmanned Aerial Vehicle (UAV) Photogrammetry Technology for Dynamic Mining Subsidence Monitoring and Parameter Inversion: A Case Study in China. IEEE Access 2020, 8, 16372-16386. [CrossRef]

(C) 2020 by the authors. Licensee MDPI, Basel, Switzerland. This article is an open access article distributed under the terms and conditions of the Creative Commons Attribution (CC BY) license (http://creativecommons.org/licenses/by/4.0/). 